\title{
ANÁLISIS INTERNO DE LAS COOPERATIVAS AGROALIMENTARIAS CATALANAS DESDE UNA PERSPECTIVA COMPARADA: LOS SECTORES DEL ACEITE Y LA FRUTA DULCE
}

\author{
POR \\ Yolanda MONTEGUT SALLA ${ }^{1} \mathrm{y}$ \\ Eduard CRISTÓBAL FRANSI
}

\section{RESUMEN}

Para poder formular estrategias y llevar a cabo actuaciones que permitan mejorar la posición competitiva de las cooperativas, es necesario realizar un análisis de las mismas. Las cooperativas agrarias, al igual que el resto de empresas, también están sometidas a cambios y por ello es necesario conocer sus puntos fuertes y débiles con la finalidad de detectar tanto oportunidades como amenazas. Hasta ahora el objetivo principal de las cooperativas ha sido el de la comercialización de los productos. Sin embargo, la nueva situación socioeconómica plantea la necesidad de que dichas entidades asuman nuevos objetivos, tales como la mejora de la calidad y la conservación del medio ambiente, nuevas estrategias de ventas, diversificación de la producción, etc... En el presente artículo se analizan las características generales del sector cooperativo en Cataluña para ver en qué grado dicho sector tiene protagonismo en las fases posteriores a la producción. Para ello, se ha realizado un estudio comparativo basado en diferentes aspectos de la estructura interna tanto de las cooperativas de fruta dulce como de las cooperativas de aceite.

\footnotetext{
${ }^{1}$ Yolanda Montegut Salla

Doctora en Administración y Dirección de Empresas. Universitat de Lleida. Dirección de correo electrónico: ymontegut@aegern.udl.cat

Eduard Cristóbal Fransi

Doctor en Economía. Universitat de Lleida. Dirección de correo electrónico: cfeduard@aegern.udl.cat
}

REVESCO Nº 108 - Segundo Cuatrimestre 2012 - ISSN: 1885-8031 - www.ucm.es/info/revesco

DOI: $10.5209 /$ rev_REVE.2012.v18.39587

Fecha de recepción: 09/02/2011

Fecha de aceptación: 09/09/2011 
Palabras clave: cooperativas agrarias, gestión, aceite, fruta, producción, financiación, comercialización.

Claves Econlit: P130, Q130, Q140,

\title{
INTERNAL ANALYSIS OF CATALAN AGRARIAN COOPERATIVES SINCE A COMPARATIVE PERSPECTIVE: THE OIL OLIVE SECTOR AND THE SWEET FRUIT SECTOR
}

\begin{abstract}
With the aim to develop strategies that allow improving the cooperatives competitive position, is necessary to realize an analysis of these organizations. Agricultural cooperatives, as the rest of business, are affected for changes. Thus it is necessary to know his strong and weak points with the purpose to detect as their opportunities as their threats. Until now the main objective of the cooperatives has been the products commercialization. However, the new socioeconomic situation poses the need that these organizations assume new objectives, such as the quality improvement, the environment conservation, new sales strategies, production diversification, etc... This present paper analyses the general characteristics of the cooperative sector in Catalonia with the aim to see which degree of prominence has in the subsequent phases to the production. In order to do this, we have realized a comparative study basing in different aspects of the internal structure of sweet fruit as well as olive oil cooperatives.
\end{abstract}

Keywords: agrarian cooperatives, management, olive oil, fruits, production, financing, commercialization.

\section{INTRODUCCIÓN}

Al igual que en otros ámbitos de la actividad económica, las cooperativas constituyen el eje básico de la Economía Social en el sector agrario, tanto por su importancia empresarial como por las características propias de su organización, que las configuran como empresas con funcionamiento y gestión democráticos y supeditación del capital a la finalidad social. 
Las cooperativas agrarias son una pieza clave para el desarrollo rural, ya que constituyen uno de los principales elementos de creación de actividad económica, mantienen la población de una zona y ofrecen servicios a los municipios que de otra manera sería difícil de disponer como pueden ser las secciones de crédito. Por tanto las cooperativas tienen un claro componente social que es utilizado para desarrollar determinados servicios sociales necesarios en el medio rural. Sin embargo el contexto social y económico actual plantea retos importantes para el cooperativismo agrario, siendo necesaria su adaptación a los nuevos tiempos y exigencias de los mercados para poder seguir siendo competitivos y al mismo tiempo constituir un instrumento de desarrollo local y de creación de actividad económica.

Es por tanto de sumo interés hoy en día conocer en profundidad el estado de nuestras empresas y el proponer pautas generales para su adaptación y mejora, así como el tratar de apoyar a las empresas a llevar adelante esos cambios. Dentro del proceso de planificación empresarial, es importante realizar un diagnóstico de la propia cooperativa con el fin de adoptar las estrategias más convenientes para la consecución de los objetivos que persiguen las cooperativas agrarias.

La finalidad de este estudio es realizar un diagnóstico interno, que persigue una análisis de factores clave en el desarrollo del cooperativismo como la actividad productiva, financiera y comercial, enmarcados en sus respectivas áreas funcionales, mediante un análisis comparativo de dos sectores cooperativos agrarios que tienen un peso relevante en Cataluña, no solamente porque son sectores muy arraigados a esta zona, sino por su contribución a la generación de empleo y al mantenimiento de las zonas rurales, así como por constituir el principal instrumento para trasladar el valor añadido de los canales de comercialización a los agricultores, actuando a su vez como elemento reestructurador de los mercados de origen.

Por tanto, el principal objetivo del presente estudio es disponer de información acerca del funcionamiento interno de las empresas cooperativas tanto del sector frutícola como del sector oleícola, a través del análisis de las diferentes áreas funcionales de una muestra de las mismas.

Este trabajo se divide en tres apartados: en el primero se realiza una revisión de la literatura; el segundo trata sobre los objetivos del mismo y la metodología seguida para conseguirlos y en el tercero se destacan los principales resultados que se extraen del estudio y 
que nos informan sobre el grado de aprovechamiento de dichos factores remarcando las diferencias y similitudes que presentan ambos sectores

\section{MARCO TEÓRICO}

A pesar de la gran importancia que tiene el movimiento cooperativo en España en general y en Cataluña en particular, las cooperativas no han sido objeto de grandes estudios. Autores como Amat (1997), Serrat (1986) y Barriach (1981) han realizado un análisis global de dichas entidades. Caballer, Julià, et al. (1987) realizan un análisis empresarial de las cooperativas agrarias en el ámbito valenciano y por otro lado, Moyano e Hidalgo (2001) estudian el impacto de la dimensión en la sociedad cooperativa agraria.

Si centramos los trabajos en el ámbito oleico, Tous (1990; 1993; 1994, a y b) analiza el cultivo del olivo, con especial referencia a Cataluña y sus Denominaciones de Origen. Asimismo, Vilá y Farrán (1991) por encargo de la Cámara de Comercio analizan la situación del aceite de oliva en la provincia de Lleida. Fortuny (2002) realiza un análisis tanto interno como externo del sector del aceite de oliva en Cataluña. Mozas (2000) analiza como se percibe el entorno competitivo específico por el conjunto de almazaras cooperativas de la provincia de Jaén. Montegut et al. (2011) realizan una tipificación de las cooperativas del sector del aceite de oliva en Cataluña.

Respecto al ámbito hortofrutícola, encontramos diferentes trabajos como los realizados por Montegut y Cristóbal (2010) donde se revisan diferentes aspectos de la gestión de las cooperativas de fruta dulce catalanas. También podemos señalar el trabajo de López Godoy y López-Cruces (2007) donde se centra en los métodos de liquidación empleados por las cooperativas españolas; Galdeano Gómez (2002) trata de determinar el impacto de las prácticas medioambientales y la mejora de la calidad en el sector cooperativo de las frutas y hortalizas frescas andaluz; también se destacan los estudios de Gómez Espín (2004); y Álvarez y Camacho (2003) donde se analizan las estrategias de innovación en el sector hortofrutícola español y en las empresas encargadas de la logística y transporte de dichos productos.

Otros trabajos como los de Vidal, Del Campo y Segura (2000) describen el cooperativismo de comercialización hortofrutícola de la Comunidad Valenciana; Cook (1997) 
analiza las tendencias en el comercio internacional de frutas y hortalizas frescas; Heijbroek, Van Dijk y Van Pelt (1997) analizan el comercio mundial de frutas frescas; Lucier, Pollack y Pérez (1997) determinan la penetración de las importaciones de frutas y hortalizas de los Estados Unidos; Segura y Server (1990) estudian la situación económico y financiera de las organizaciones de productores de frutas y hortalizas en la Comunidad Valenciana. Galdeano (2000; 2001) pone de relieve las estrategias y la posición competitiva de las entidades asociativas (cooperativas y sociedades agrarias de transformación) de comercialización hortofrutícola localizadas en el sureste español en la actual estructura de mercado. Posteriormente, Galdeano (2002) estudia el impacto que las acciones de calidad tienen sobre un conjunto de cooperativas hortofrutícolas andaluzas durante el período 1997/2000. Finalmente encontramos la investigación de Montegut y Cristóbal (2009) donde se analiza el uso que las cooperativas hortofrutícolas catalanas hacen de Internet.

Factores tales como la estructura productiva, la innovación y la comercialización son determinantes para mejorar la competitividad de las cooperativas. Trabajos como los realizados por Camelo et al. (2000) o Molina y Conca, (2000), consideran la innovación como un medio para la consecución de ventajas competitivas sostenibles en el tiempo.

Otros autores como García-Álvarez-Coque et al. (2006), resaltan la importancia de la estructura productiva y comercial como mecanismos para adaptase a los mercados y ser más competitivos. También Shohan, (1999) y Aulakh et al. (2000), han destacado la importancia de la gestión de marketing como un factor relevante para elevar la competitividad de las empresas.

Por otro lado, Ruiz Jiménez et al. (2006) analizan las cooperativas agrarias y detectan la imperiosa necesidad que se tiene en un mercado tan competitivo como el actual, de crecimiento e internacionalización de las organizaciones.

\section{METODOLOGÍA}

La metodología seguida para alcanzar los objetivos del presente estudio ha sido la obtención de información a través de un trabajo de campo basado en un cuestionario estructurado. Para la elaboración de un cuestionario completo y significativo, se realizaron una serie de entrevistas en profundidad para ver el estado de la cuestión y poder tener 
información previa. A su vez, se realizó una profunda revisión de la literatura existente, así como de trabajos previos, para implementar la encuesta de base.

Una vez realizado el cuestionario y con el objeto de identificar posibles ambigüedades u otros problemas potenciales, fue sometido a una prueba preliminar, administrándolo a una pequeña muestra de personas objeto de la investigación. Tras efectuar el pretest se realizó el cuestionario definitivo y se cumplimentó mediante entrevistas personales a los gerentes, o en su defecto, presidentes de las cooperativas. Las características generales de la técnica de muestreo utilizada se reflejan en el cuadro 1. En el mismo se observa que el total de cuestionarios válidos cumplimentados fueron de 46 para el sector fruta dulce y de 70 para el sector del aceite.

El cuestionario se divide en diferentes apartados que aportan información de todos los ámbitos de la cooperativa: características generales, actividad productiva, actividad financiera y actividad comercial. 
Cuadro 1. Cuadro resumen de la técnica de muestreo

\begin{tabular}{|l|l|l|}
\hline Población & $\begin{array}{l}72 \text { cooperativas productoras de } \\
\text { fruta dulce }\end{array}$ & $\begin{array}{l}131 \text { cooperativas productoras de aceite de } \\
\text { oliva }\end{array}$ \\
\hline Ámbito geográfico & Cataluña & Cataluña \\
\hline Muestra & $\begin{array}{l}46 \text { encuestas con un margen de } \\
\text { error de } \pm 8,9 \% \text { y nivel de } \\
\text { confianza de } 95,5 \%(\mathrm{k}=2 \mathrm{y} \\
\mathrm{P}=\mathrm{Q}=50 \%)\end{array}$ & $\begin{array}{l}70 \text { encuestas con un margen de error de } \\
\pm 8,3 \% \text { y nivel de confianza de } 95,5 \% \\
(\mathrm{k}=2 \mathrm{y} \mathrm{P}=\mathrm{Q}=50 \%)\end{array}$ \\
\hline Procedimiento & Muestreo aleatorio simple & Muestreo aleatorio simple \\
\hline $\begin{array}{l}\text { Administración de la } \\
\text { encuesta }\end{array}$ & $\begin{array}{l}\text { Entrevista personal a los } \\
\text { presidentes o gerentes de las } \\
\text { cooperativas }\end{array}$ & $\begin{array}{l}\text { Entrevista personal a los presidentes o } \\
\text { gerentes de las cooperativas }\end{array}$ \\
\hline
\end{tabular}

Fuente: elaboración propia

\section{ANÁLISIS EXPLORATORIO DE LOS RESULTADOS}

\subsection{Características generales}

En Cataluña, gran parte de las almazaras cooperativas se crearon entre 1910 y 1920. No es hasta la década de los 40 y 50 que proliferan nuevas cooperativas, una vez ya finalizada la Guerra Civil. A partir de aquí, prácticamente no se ha creado nuevas formas cooperativas. Se trata, por tanto de empresas maduras.

Por el contrario, las cooperativas de fruta dulce se han ido creando en los últimos 40 años, debido sobretodo a la reconversión paulatina de tierras de secano en tierras de regadío. Muchas zonas donde antes predominaban cultivos de secano como el olivo, almendro y viñedo, ahora con la introducción del riego (pantanos, canales, etc.), se han reconvertido en plantaciones con otro tipo de cultivo como la fruta dulce (ver cuadro 2).

\footnotetext{
${ }^{2}$ El sector de frutas, hortalizas y legumbres, englobado en la categoría hortofrutícola, está formado por cítricos, frutos secos, hortalizas, legumbres y fruta dulce. Según datos de la Confederación de Cooperativas Agrarias de España (CCAE) en Cataluña, existen actualmente 72 cooperativas productoras de fruta dulce.

${ }^{3}$ El sector del aceite de oliva se engloba, según el código de actividad a efectos del Impuesto de Actividades Económicas (IAE) en el 411: fabricación de aceite de oliva. Esta actividad se encuadra en el código 41 que está formado por las industrias de productos alimentarios, bebidas y tabaco. A través de las Cámaras de Comercio catalanas, se nos ha facilitado un listado de todas aquellas empresas cuyos códigos de actividades son el 4111 (fabricación y envasado de aceite de oliva) y 4112 (fabricación de aceite de oliva). Según los datos facilitados, existen 189 empresas inscritas con el código 4112, de las cuales 119 son cooperativas; y existen 62 empresas inscritas con el código 4111, de las cuales 23 son cooperativas. En total, resultan 219 almazaras, de las cuales 131 son cooperativas.
} 
Cuadro 2. Año de fundación de las cooperativas

\begin{tabular}{|c|c|c|c|c|}
\hline \multirow[b]{2}{*}{ Años } & \multicolumn{2}{|c|}{ Cooperativas Aceite } & \multicolumn{2}{|c|}{ Cooperativas fruta dulce } \\
\hline & $\begin{array}{l}\text { Número de } \\
\text { cooperativas }\end{array}$ & $\%$ & $\begin{array}{l}\text { Número de } \\
\text { cooperativas }\end{array}$ & $\%$ \\
\hline Anterior a 1899 & 1 & 1.42 & - & - \\
\hline 1900-1909 & 5 & 7.14 & - & - \\
\hline 1910-1919 & 16 & 22.85 & 3 & 6,7 \\
\hline 1920-1929 & 8 & 11.42 & - & - \\
\hline 1930-1939 & 3 & 4.28 & - & - \\
\hline 1940-1949 & 12 & 17.14 & 6 & 13,6 \\
\hline $1950-1959$ & 13 & 18.57 & 5 & 11,4 \\
\hline 1960-1969 & 6 & 8.57 & 8 & 18,2 \\
\hline 1970-1979 & 1 & 1.42 & 7 & 15,7 \\
\hline 1980-1989 & 5 & 7.14 & 6 & 13,5 \\
\hline 1990-1999 & - & - & 8 & 18,7 \\
\hline 1999-2008 & - & - & 1 & 2,2 \\
\hline TOTAL & 70 & 100 & 46 & 100 \\
\hline
\end{tabular}

Fuente: elaboración propia

Barea y Monzón en El Libro Blanco de la Economía Social en España (1992), también establecen que las cooperativas agrarias, se caracterizan por su pequeña dimensión, en general insuficiente para hacer frente con garantías de éxito a las exigencias de mercado. En España, las cooperativas agrarias presentan una cifra media de 266 socios por entidad.

Si examinamos la memoria de estas cooperativas la mayoría de ellas presentan un objeto social muy amplio. La diversificación de actividades por parte de las cooperativas frutícolas da lugar a lo que en terminología propia del sector se llama secciones (ver figura 1). La mayor parte de las cooperativas frutícolas comparten la sección de fruta con otras secciones como la de suministros agrícolas y ventas de fertilizantes y productos fitosanitarios $(47,8 \%)$, sección de crédito $(23,9 \%)$ y agro tienda $(15,2 \%)$. Únicamente un $8,7 \%$ disponen también de sección de vino y de frutos secos. Las almazaras cooperativas comparten la sección de aceite con otras secciones como la de almendra (64\%), suministros agrícolas y ventas de fertilizantes y productos fitosanitarios (59\%) y agro tienda (59\%). Únicamente un $37 \%$ dispone también de sección de vino y un 47\% dispone de sección de crédito. 
Figura 1. Secciones distintas a la actividad principal (\%)

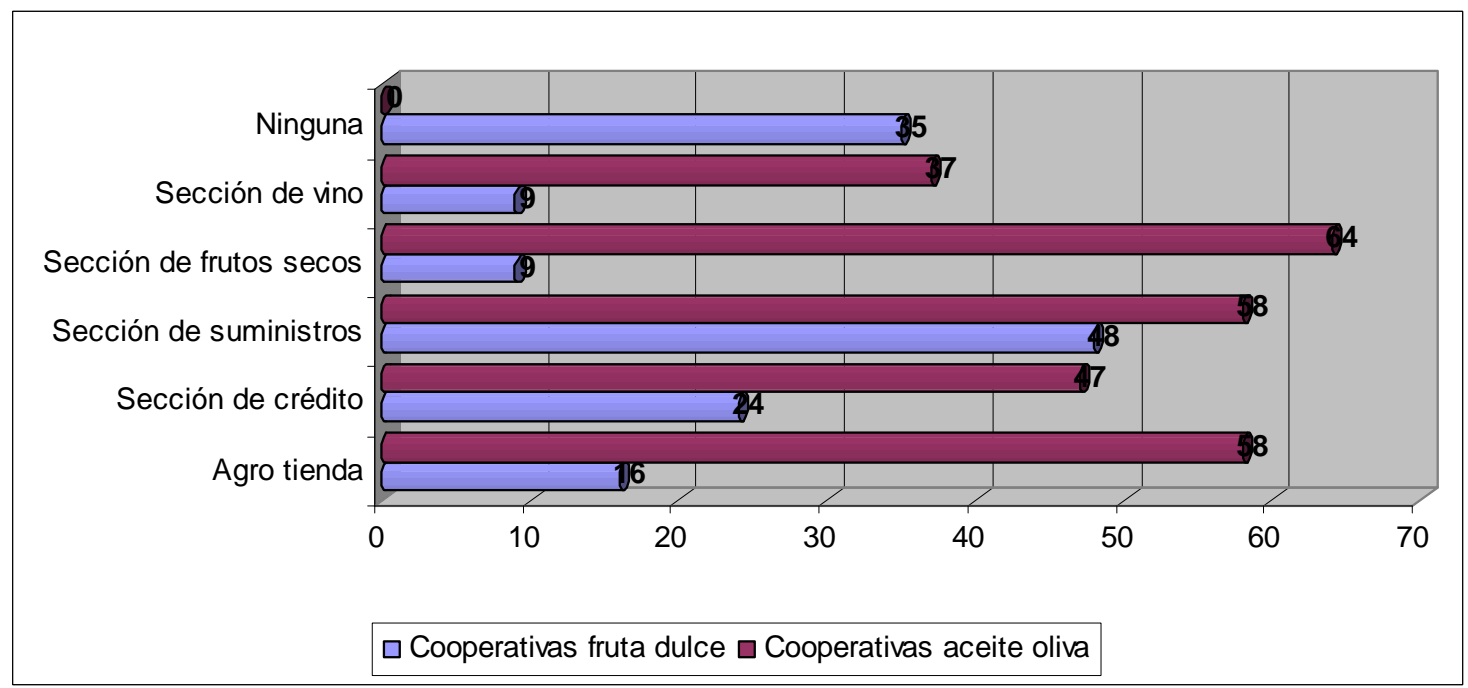

Fuente: elaboración propia

Este tipo de estructuras es congruente con un modelo de crecimiento de la cooperativa basado en la consolidación de una actividad principal y la asunción de nuevas actividades productivas como respuesta a las necesidades de los socios. Frente a este modelo de crecimiento podríamos situar otro por volumen de producción. Sin embargo en el sector agrario y en el oleícola en particular dicho crecimiento solo se puede conseguir mediante la admisión de nuevos socios que aporten su cosecha a la cooperativa o bien aumentando la producción de cada socio mediante el empleo de técnicas de cultivo más modernas que aumenten los rendimientos de los olivos. Actualmente, la mejora del cultivo se empieza a conseguir con la implantación del riego de apoyo a los olivos y la creación de nuevas plantaciones más intensivas, aunque este proceso es lento. Por el contrario, las cooperativas de fruta dulce suelen realizar un solo tipo de actividad, aunque ofrecen otros servicios al socio, que no son únicamente la comercialización de la fruta aportada por los mismos, como es el abastecimiento de suministros.

Las sociedades cooperativas, cuyo último objetivo es la supervivencia, necesitan, sin perder su condición empresarial, acometer procesos de concentración para ser capaces de competir, junto con el resto de empresas, en el mercado. La mayoría de las cooperativas objeto de estudio son de pequeña dimensión. Se puede indicar que tanto por la cifra de negocios como por el número de trabajadores se trata de pequeñas y medianas empresas. La participación de cooperativas agrarias españolas en el mercado es menor al de sus homólogas europeas, debido principalmente a este menor tamaño empresarial. Por ello es esencial 
impulsar los procesos de concentración o asociación intercooperativos, los cuales se reducen en la práctica a la constitución de cooperativas de segundo grado.

En el estudio realizado, un $32,6 \%$ de las cooperativas de fruta analizadas están integradas en alguna entidad de segundo grado. La mayor parte de las que contestan están asociadas a ACTEL, sobretodo en su sección de suministros. Para el caso de las almazaras cooperativas, un 56\% están integradas en alguna entidad de segundo grado. Un $29 \%$ de las almazaras cooperativas están asociadas a Unió Agraria Reus y tan solo un 15\% lo están a Agrolés y Ceolpe. Las almazaras cooperativas están asociadas a estas tres cooperativas de segundo grado en la sección de aceite de que disponen. Cabe tener en cuenta que una cooperativa puede estar asociada a más de un entidad de segundo grado. Así por ejemplo algunas almazaras cooperativas están asociadas a la sección de aceite de una cooperativa de segundo grado y al mismo tiempo están asociadas a otra entidad de segundo grado en su sección de suministros.

Con estos resultados podemos corroborar que el grado de asociacionismo no es muy alto, sobretodo en las cooperativas de fruta dulce. Sin embargo, las almazaras cooperativas están asociadas en un porcentaje superior, sobretodo con la finalidad de comercializar conjuntamente el aceite, que es el fin básico de las cooperativas de segundo grado de aceite. Ruben (2007) destaca la importancia de cooperar en la fase de comercialización por parte de las cooperativas.

Si bien a nivel económico la integración asociativa se realiza mediante cooperativas de segundo grado, la integración asociativa a nivel político de las estructuras cooperativas se realiza a través de federaciones de cooperativas. Los servicios prestados por estas federaciones suelen ser de asesoramiento bien de carácter económico, contable, agrícola, laboral, fiscal, jurídico y comercial. También se encargan de tener informadas a las cooperativas sobre todos aquellos asuntos de carácter general, así como de las relaciones con los Organismos Oficiales para las diversas gestiones, fundamentalmente relacionadas con la obtención de subvenciones. Por el contrario los servicios prestados por las cooperativas de segundo grado, no suelen ser tan amplios y están más orientados a la comercialización del producto. Las organizaciones cooperativas agrarias españolas muestran una mayor sensibilidad hacia lo que podemos denominar intercooperación en el plano político o representativo frente a la intercooperación en el plano económico. Así mientras las 
cooperativas afiliadas a una federación u organización representativa se cifra en el 57,2\%, tan solo el 46,2\% forma parte de alguna cooperativa de segundo grado (Libro Blanco de la Economía Social en España, 1992).

En el estudio realizado, el 65,2\% de las cooperativas de fruta dulce y el $85 \%$ de las cooperativas de aceite de oliva, están asociadas a la Federación de Cooperativas Agrarias de Cataluña (FCAC). Por tanto, podemos constatar que si bien existe un elevado grado de integración, éste es básicamente en federaciones más que en entidades de grado superior.

\subsection{Recursos Humanos}

Si analizamos el número de socios, el principio cooperativo de puertas abiertas hace que este parámetro, indicativo de la dimensión de la cooperativa haya de ser referido a un determinado momento. Podemos observar, como en general, se trata de empresas de pequeña dimensión, puesto que la mayoría de ellas se encuentra en el intervalo de 50-500 socios (cuadro 3). Según datos del Anuario Socioeconómico de las Cooperativas Agrarias de Cataluña de la Federación de Cooperativas Agrarias de Cataluña (2009), las cooperativas agrarias catalanas de primer grado tienen una media de 286,3 socios.

Cuadro 3. Estructura de las cooperativas productoras de aceite de oliva y fruta dulce en Cataluña según el número de socios

\begin{tabular}{|l|c|c|c|c|}
\hline \multirow{2}{*}{$\begin{array}{c}\text { Número de socios por } \\
\text { intervalos }\end{array}$} & \multicolumn{2}{|c|}{ Cooperativas fruta dulce } & \multicolumn{2}{c|}{ Cooperativas aceite oliva } \\
\cline { 2 - 5 } & $\begin{array}{c}\text { Número de } \\
\text { cooperativas }\end{array}$ & $\mathbf{\%}$ & $\begin{array}{c}\text { Número de } \\
\text { cooperativas }\end{array}$ & $\%$ \\
\hline $0-50$ & 16 & 34,8 & 9 & 12,9 \\
$51-200$ & 19 & 41,3 & 31 & 44,3 \\
$201-500$ & 10 & 21,7 & 21 & 30 \\
$501-1.000$ & 1 & 2,2 & 7 & 10 \\
Más de 1.000 & 0 & 0 & 2 & 2,9 \\
\hline TOTAL & $\mathbf{4 6}$ & $\mathbf{1 0 0}$ & $\mathbf{7 0}$ & $\mathbf{1 0 0}$ \\
\hline
\end{tabular}

En la política de admisión de nuevos socios, a pesar de que todas admiten el principio de puertas abiertas, en la realidad las entidades suelen establecer algún tipo de restricción a la hora de admitir un nuevo socio. Si analizamos los resultados de nuestro estudio, casi una tercera parte de las cooperativas frutícolas $(32,6 \%)$ respetan el principio de puertas abiertas. El resto establece algún tipo de restricción. Concretamente, un 8,7\% solo admite familiares de socios, un $13 \%$ no admite nuevos socios y un significativo $39,1 \%$ establecen otras condiciones de admisión como puede ser, admisión en función de la producción, que sean de 
la zona, o que en los Estatutos de la cooperativa se encuentre algún criterio específico de admisión.

En el caso de las almazaras cooperativas, los resultados son similares. Más de la mitad de las almazaras cooperativas (61\%) respetan el principio de puertas abiertas. El 39\% restante establece algún tipo de restricción. Concretamente, un 14\% solo admite familiares de socios, un $10 \%$ no admite nuevos socios y un $11 \%$ establecen otras condiciones de admisión.

La mayor parte de los socios de estas cooperativas son agricultores con una media de edad alta, con un porcentaje de gente joven muy bajo, tal como muestra el cuadro 4. Más del $90 \%$ de los socios tiene entre 40 y 60 años. Según datos de la Confederación de Cooperativas Agrarias de Cataluña (2004), las cooperativas agrarias se encuentran en el segmento de edad de los socios mayores de 56 años, siendo la actividad que engloba el grupo de mayor edad de los socios.

Cuadro 4. Edad de los socios

\begin{tabular}{|l|c|c|c|c|}
\hline \multirow{2}{*}{ Intervalos de edad } & \multicolumn{2}{|c|}{ Cooperativas fruta dulce } & \multicolumn{2}{c|}{ Cooperativas aceite oliva } \\
\cline { 2 - 5 } & $\begin{array}{c}\text { Número de } \\
\text { cooperativas }\end{array}$ & $\%$ & $\begin{array}{c}\text { Número de } \\
\text { cooperativas }\end{array}$ & $\%$ \\
\hline De 20 a 30 años & 0 & 0 & 1 & 1,4 \\
De 31 a 40 años & 4 & 8,7 & 1 & 1,4 \\
De 41 a 50 años & 29 & 63,0 & 38 & 34,3 \\
De 51 a 60 años & 13 & 28,3 & 5 & 7,3 \\
Más de 60 años & 0 & 0 & 1 & 1,4 \\
NS/NC & 0 & 0 & $\mathbf{7 0}$ & $\mathbf{1 0 0}$ \\
\hline TOTAL & \multicolumn{2}{|c|}{ Fuente: elaboración propia } & \\
\hline
\end{tabular}

Sin embargo, los resultados también nos muestran como a diferencia de las cooperativas de aceite de oliva donde el principal segmento se encuentra en el intervalo 5060, las cooperativas frutícolas se enmarcan en el intervalo 40-50. Este hecho puede ser debido, a que a pesar de que la población ocupada en el campo ha ido experimentando un progresivo envejecimiento, la reconversión paulatina de tierras de secano en tierras de regadío, ha animado a la gente joven a realizar inversiones en las plantaciones con nuevos tipos de cultivo, como la fruta dulce.

Respecto a las actividades de formación, los resultados muestran como prácticamente la totalidad de las mismas, alrededor de un 63\%, realizan este tipo de actividades. Según datos de la Confederación de Cooperativas Agrarias de Cataluña (2004), no solo las cooperativas agrarias, sino todas las cooperativas en general, realizan cursos de formación. En el caso 
concreto de las cooperativas agrarias, el $96 \%$ de las mismas realizan cursos de formación, generalmente entre 2 y 5 veces al año.

Figura 2. Destinatarios de los curso de formación en la cooperativa (\%)

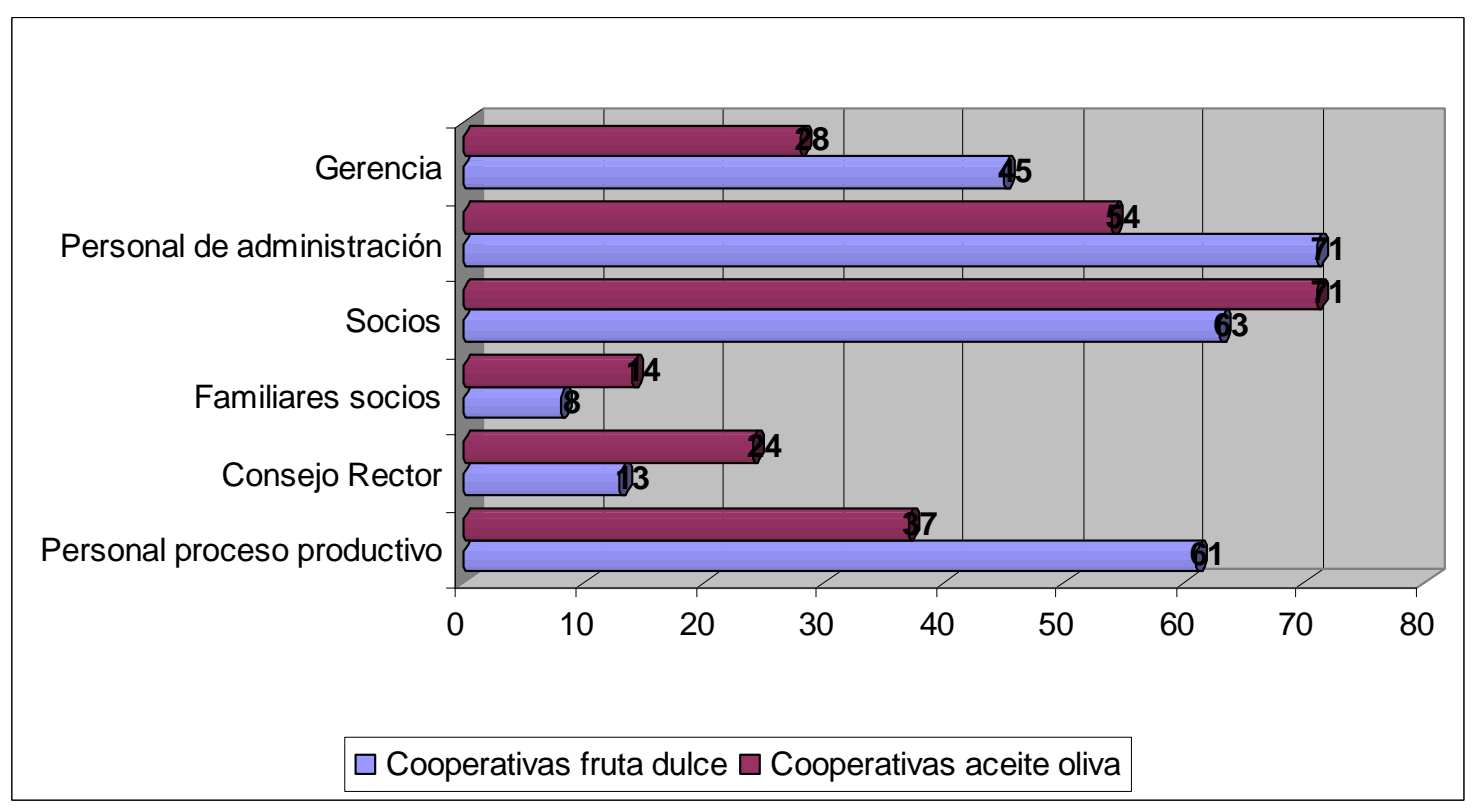

Fuente: elaboración propia

La figura 2, muestra como en el caso de las almazaras cooperativas, la mayor parte de los cursos van destinados a la formación del socio y del personal de administración. Muy pocas cooperativas (aproximadamente un 20\%) realizan cursos de formación al consejo rector, gerencia, a familiares de los socios, o al personal dedicado al proceso productivo. En las cooperativas de fruta dulce, la mayor parte de los cursos no solamente van destinados a los socios, sino también a la formación del personal de administración y al personal dedicado al proceso productivo. Normalmente se trata de cursos de prevención de riesgos laborales y cursos relacionados con la calidad del producto.

Por tanto, aunque ambos tipos de entidades suelen realizar de forma habitual cursos de formación, en el caso de las cooperativas de fruta, éstos van dedicados a un público más amplio que en el caso de las almazaras cooperativas, donde los cursos van prácticamente dirigidos a un público concreto como es el socio.

Las cooperativas por otra parte también pueden disponer de órganos de control como los interventores de cuentas y el comité de recursos. Los interventores fiscalizan la gestión del Consejo Rector y comprueban la documentación y contabilidad de dichas entidades. En el 
caso de las cooperativas frutícolas, los interventores de cuentas desempeñan la función en el $45,7 \%$ de los casos. Igual cifra representa el control de la gestión económica llevado a cabo por auditores externos que la ley de cooperativas en su artículo 52 establece. Cabe señalar que en un 6,5\% de los casos afirman no realizar un control de la gestión económica. Vidal (1999) también establece que es práctica común del cooperativismo hortofrutícola valenciano recurrir a algún tipo de asesoramiento externo básicamente de carácter fiscal, aunque también es común el asesoramiento técnico.

En el caso de las almazaras cooperativas, los interventores de cuentas desempeñan la función en el 17\% de los casos. En el resto de los casos el control de la gestión económica es llevado a cabo por auditores externos. En un estudio realizado por Mozas (2000), tan solo el $17,6 \%$ de las almazaras cooperativas jienenses habían utilizado alguna vez este mecanismo de control externo. Por tanto podemos observar como ambos sectores suelen utilizar en gran medida las auditorías externas como medio de control económico. Cabe tener presente que la mayoría de dichas entidades disponen de sección de crédito y en este caso está establecido por ley que el control sea llevado a cabo por Auditores.

A nivel de dirección y administración aparece otra figura, no menos importante, que es la de gerente, que muchas veces se confunde con la figura de dirección. En las cooperativas frutícolas catalanas, un 21,7\% de las mismas no disponen de gerente. En el resto de los casos encontramos que en un $28,3 \%$ es socio de la misma y en un 47,8 \% está contratado. En las cooperativas productoras de aceite de oliva, los resultados difieren un poco puesto que un $39 \%$ de las mismas no disponen de gerente, cifra algo superior al otro sector agrario. La relación del gerente con la entidad puede ser de socio (un $30 \%$ ) y de no socio (un $32 \%$ ). La figura del gerente, si bien en muchos casos puede producir un cierto rechazo, se traduce en una mayor profesionalización de la gestión.

En cuanto a su nivel de formación, gran parte de los cursos que ofrece la cooperativa tampoco van destinados al gerente como ya hemos indicado anteriormente. En el caso de las almazaras cooperativas, los gerentes, tienen una formación de grado medio (32\%) o superior (34\%). En un 12\% de los casos el gerente tiene formación específica para el puesto que ocupa y tan solo en un $7 \%$ dispone de estudios elementales. Para las cooperativas de fruta dulce, el gerente tiene una formación de grado medio en el $26,1 \%$ de los casos y en el 32,6\% de los 
casos superior. En un 4,3\% de los casos el gerente tiene formación específica para el puesto que ocupa y tan solo en un 10,9\% dispone de estudios elementales.

Si analizamos el personal contratado hemos de tener en cuenta que el funcionamiento de dicho tipo de sociedades requiere de poco personal por tratarse de actividades estacionales. En este caso habrá personal contratado todo el año y personal contratado únicamente en los períodos de campaña que aumenta o disminuye en función de la producción obtenida de fruta $\mathrm{y}$ aceitunas.

Los resultados del estudio muestran que en ambos sectores el intervalo de trabajadores, tanto fijos como eventuales se encuentra entre 1 y 10, tal como queda reflejado en el cuadros 5. El Ministerio de Agricultura, Pesca y Alimentación en el Libro Blanco de la Agricultura y el Desarrollo Rural (2002) establece que las empresas agroalimentarias son principalmente de reducido tamaño, entre 1 y 9 empleados o sin ningún asalariado. La dimensión media es de 7 empleados por establecimiento.

Cuadro 5. Tipología de trabajadores de las cooperativas

\begin{tabular}{|l|c|c|c|c|c|c|c|c|}
\hline & \multicolumn{3}{|c|}{ Trabajadores Fijos } & \multicolumn{3}{c|}{ Trabajadores eventuales } \\
\hline & $\begin{array}{c}\text { Cooperativas fruta } \\
\text { dulce }\end{array}$ & $\begin{array}{c}\text { Cooperativas aceite } \\
\text { oliva }\end{array}$ & \multicolumn{2}{c|}{$\begin{array}{c}\text { Cooperativas fruta } \\
\text { dulce }\end{array}$} & $\begin{array}{c}\text { Cooperativas aceite } \\
\text { oliva }\end{array}$ \\
\hline $\begin{array}{l}\text { Número de } \\
\text { trabajadores }\end{array}$ & $\begin{array}{c}\text { Número de } \\
\text { cooperativas }\end{array}$ & $\%$ & $\begin{array}{c}\text { Número de } \\
\text { cooperativas }\end{array}$ & $\%$ & $\begin{array}{c}\text { Número de } \\
\text { cooperativas }\end{array}$ & $\%$ & $\begin{array}{c}\text { Número de } \\
\text { cooperativas }\end{array}$ & $\%$ \\
\hline 0 empleados & - & - & - & - & 0 & 0 & 4 & 5,7 \\
1-5 empleados & 22 & 47,8 & 46 & 65,7 & 16 & 34,8 & 42 & 60 \\
6-10 empleados & 11 & 23,9 & 11 & 15,7 & 9 & 19,6 & 9 & 12,9 \\
11-20 empleados & 9 & 19,6 & 5 & 7,1 & 6 & 13,0 & 2 & 2,9 \\
21-40 empleados & 1 & 2,2 & 2 & 2,9 & 10 & 21,2 & 2 & 2,9 \\
41-80 empleados & - & - & 1 & 1,4 & - & - & - & - \\
Más de 81 empleados & 1 & 2,2 & 1 & 1,4 & - & - & - & - \\
NS/NC & 2 & 4,3 & 4 & 5,7 & 5 & 10,9 & 9 & 12,9 \\
\hline TOTAL & $\mathbf{4 6}$ & $\mathbf{1 0 0}$ & $\mathbf{7 0}$ & $\mathbf{1 0 0}$ & $\mathbf{4 6}$ & $\mathbf{1 0 0}$ & $\mathbf{7 0}$ & $\mathbf{1 0 0}$ \\
\hline
\end{tabular}

Un dato a señalar es que no hay ninguna cooperativa de fruta dulce que tenga 0 trabajadores eventuales, aspecto que sí sucede con las almazaras cooperativas. Además un $21 \%$ de las cooperativas frutícolas tiene más de 20 empleados eventuales, lo que nos hace pensar que el proceso posterior a la recogida del producto (fruta o aceitunas), en el caso de las cooperativas frutícolas es un poco más complejo y requiere una mayor mano de obra para manipular, seleccionar y envasar el producto. Por el contrario, en las almazaras cooperativas el proceso de obtención de aceite está muy mecanizado, sobretodo debido a la diferencia en el 
tipo de producto que no es tan perecedero ni tan frágil como puede ser la fruta dulce que debe ser tratada adecuadamente.

\subsection{Actividad Productiva}

Actualmente las cooperativas deben adaptarse a los nuevos cambios. Es necesario ir modernizando la maquinaria y las instalaciones debido a la exigencia por parte del mercado de nuevos y mejores productos. Es clara la necesidad de modernizar el aparato productivo de las cooperativas. Además, la producción y el consumo han variado sensiblemente en los últimos años. Por otro lado cada vez hay un mayor nivel de exigencias de productos y servicios, dando lugar a la aparición de nuevos productos y nuevos competidores. Todos estos aspectos obligan a las cooperativas ha introducir cambios en sus sistemas de producción para adecuarse al mercado.

En los tres últimos lustros el dominio de las grandes cadenas de supermercados en la distribución y venta del producto final y la sensibilización creciente de los consumidores por la seguridad alimentaria y el medio ambiente (Del Pino, 2001), han comportado una repercusión en cascada de toda una serie de normas y estándares públicos y privados. Estas exigencias se han trasladado tanto al sector oleícola como al sector frutícola que han ido introduciendo cambios y mejoras en el ámbito productivo.

Los resultados del estudio (ver figura 3) muestran que tanto las cooperativas de fruta dulce como las cooperativas de aceite han introducido cambios a nivel de producción o de algún equipamiento. Sin embargo en función de la tipología de la cooperativa los resultados presentan ciertas diferencias. 
Figura 3. Cambios introducidos por las cooperativas en los últimos 10 años

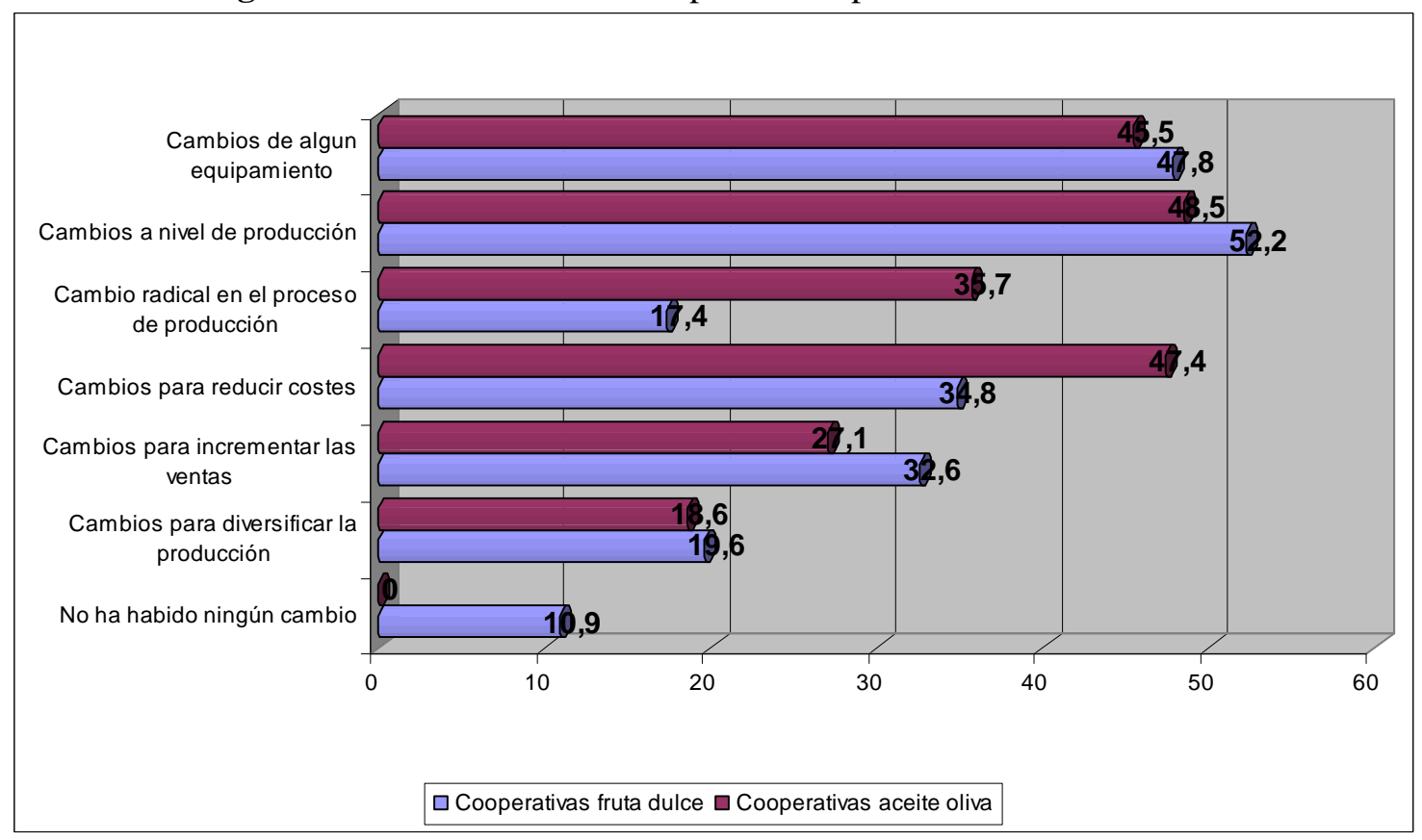

Fuente: elaboración propia

En el cooperativismo de comercialización frutícola, las inversiones con mayor relevancia en el funcionamiento de la cooperativa en los últimos 10 años destacan por este orden, las inversiones a nivel de producción y en algún equipamiento. Se trata básicamente de inversiones en instalaciones (principalmente de conservación y confección), terrenos y edificaciones.

En relación con las innovaciones en terrenos, se han introducido cambios con objeto de superar la falta o mala calidad del suelo y del agua, así como lograr una mayor productividad en ellos. De esta forma se han introducido sistemas de cubiertas que permitan proteger el cultivo del pedrisco, heladas, etc., así como nuevos sistemas de riego como el riego localizado, sobretodo en su modalidad de goteo. También se han realizado mejoras genéticas con objeto de obtener nuevas variedades que incorporen valores añadidos de manipulación, color, tamaño o sabor, al mismo tiempo que permite tener una mayor cuota de mercado.

Las innovaciones en instalaciones y edificaciones se refieren a innovaciones relacionadas con la manipulación, almacenamiento y transporte de los productos. En este proceso que se alarga desde el campo, con el consiguiente transporte en origen hasta la cooperativa donde se acondiciona y prepara el producto, clasificándolo y envasándolo, y el 
posterior transporte a los distintos destinos, sea mercado interior o exterior, predominan innovaciones con objeto de mejorar la calidad del producto.

En origen, la manipulación del producto con objeto de realizar las labores de limpieza, selección, envasado, almacenaje, conservación en frío, etc. se apuesta por introducir tecnología a lo largo de todo el proceso para facilitar el acondicionamiento y reducir la mano de obra y los tiempos de trabajo. Innovaciones en las cadenas de preparar embalajes (sobretodo cartonajes), en las de selección de producto según tamaño y color, en las de envasado (papel, plástico...), en la paletización de todo el proceso que permita su fácil y ágil desplazamiento por toda la entidad, así como los distintos almacenamientos y sobre todo la carga y descarga en los vehículos.

Los principales cambios introducidos en el sector oleícola también se han originado a nivel de producción y de algún equipamiento. Son cambios que afectan prácticamente a todas las cooperativas, como son: cambio del sistema de almacenaje, modernización de las máquinas de envasar y etiquetaje, mejora del sistema de limpieza de las aceitunas, la centrifugadora, etc. Todo ello ha permitido no solo una reducción en los costes sino también un incremento en la calidad y mejora de la presentación del producto (Cristóbal, Montegut y Marimón, 2007).

Podemos observar, como el porcentaje de cooperativas que han realizado cambios radicales en el proceso de producción es superior en las del aceite que en las de la fruta. Este factor es debido al problema que presentan las almazaras cooperativas en relación con los residuos que generan en la producción del aceite. Debido a las exigencias cada vez mayores por parte de Medioambiente en relación con el tratamiento del residuo más contaminante de las almazaras como es el alpechín, gran parte de las cooperativas oleícolas se han visto obligadas a introducir grandes cambios en sus sistemas tradicionales de producción, como ha sido el paso de un sistema de producción de tres fases, que generaba un alto nivel de residuos, a un sistema continuo de producción en 2 fases que no genera residuos ${ }^{4}$.

\footnotetext{
${ }^{4}$ Existen dos procesos distintos de extracción del aceite. El primer procedimiento llamado tradicional consiste en separar el líquido de la masa sólida mediante presión. El otro proceso, llamado continuo, separa el líquido de la masa sólida mediante centrifugación con lo que se consigue realizar el procedimiento en tres fases: la primera está compuesta por los trozos de huesos de los frutos que constituye el orujo, la segunda por agua de vegetación muy diluida llamada alpechín y la tercera fase es precisamente la del aceite. En los últimos años, ha aparecido un tercer sistema llamado continuo en dos fases, puesto que únicamente necesita dos fases para obtener el aceite y necesita menos cantidad de agua por lo que se reduce drásticamente el problema de la contaminación, ya que se
} 
Este aspecto también explicaría porque todas las almazaras cooperativas han realizado cambios, que pueden ser más o menos importantes, en el sistema productivo. Las que por determinados motivos, sobretodo de liquidez, no han podido realizar dichas innovaciones se han visto obligadas a trasladar la producción a otras entidades cooperativas. Hay que tener presente que actualmente conviven en el sector 2 tipos de instalaciones para la obtención del aceite de oliva: el tradicional de prensa y el continuo.

Por el contrario, las cooperativas de fruta dulce no presentan este problema, al no generar residuos, por lo que no se han visto obligadas a realizar cambios radicales en los sistemas de producción. Las que lo han hecho ha sido por decisión propia para adaptarse en mejores condiciones a las exigencias del mercado. Este aspecto explica que algunas cooperativas no hayan introducido cambios. Es bien conocido que en general las cooperativas tienen enormes problemas de liquidez, por lo que no siempre pueden llevar a cabo las políticas de mejora que quieren. Además ya hemos indicado que dichas entidades se caracterizan por su reducida dimensión, lo que dificulta en mayor medida el poder realizar inversiones.

A pesar de estas diferencias, queda claro que los principales motivos de inversión en las cooperativas son la ampliación o adecuación de las instalaciones productivas ante las exigencias actuales que puedan plantearse en los procesos de comercialización de los productos que ofrecen. Las mejoras en los procesos internos (inversión en informática) o la adecuación y promoción de su plantilla (inversión en personal) ocupan un nivel muy reducido y en algunos casos inexistente. Nieto (2001) destaca la importancia de la incorporación de nueva maquinaria y equipos de producción como fuente de innovación para las entidades. Dichas innovaciones pueden tener efectos sobre la organización y crear ventaja competitiva.

Respecto a la producción existen diferencias en función del tipo de cooperativa como podemos observar en el cuadro 6. 
Cuadro 6. Nivel de producción

\begin{tabular}{|l|l|l|l|l|}
\hline \multirow{2}{*}{ Toneladas } & Cooperativas fruta dulce & Cooperativas aceite oliva \\
\cline { 2 - 5 } & $\mathbf{N}^{\mathbf{0}}$ cooperativas & $\mathbf{\%}$ & $\mathbf{N}^{\mathbf{0}}$ cooperativas & $\%$ \\
\hline De $0-25$ & 8 & 17,4 & 13 & 18,6 \\
De $26-100$ & 2 & 4,3 & 25 & 35,7 \\
De $101-250$ & 5 & 10,9 & 15 & 21,4 \\
De $251-500$ & 5 & 10,9 & 8 & 11,4 \\
Más de 501 & 24 & 52,2 & 7 & 10 \\
NS/NC & 2 & 4,3 & 2 & 1,4 \\
\hline TOTAL & $\mathbf{4 6}$ & $\mathbf{1 0 0}$ & $\mathbf{7 0}$ \\
\hline
\end{tabular}

En las cooperativas de fruta dulce, la producción media de fruta es relativamente importante ya que el más de la mitad de las cooperativas encuestadas afirma que producen más de 500 toneladas de fruta. En las almazaras cooperativas la producción no es muy elevada, puesto que se sitúa entre las 26 y las 250 toneladas de aceite. Tan solo 7 de las cooperativas analizadas obtienen más de 500 toneladas de aceite.

En relación a la facturación los resultados son más similares aunque las cooperativas del sector de la fruta dulce tienen una facturación superior a las almazaras cooperativas, tal como muestra el cuadro 7.

En ambos tipos de cooperativas, más del $50 \%$ factura 300.000 y 3 millones de euros, dependiendo de la producción de la campaña. Sin embargo, hay que tener presente que el 33\% de las cooperativas de fruta dulce factura entre 1,2 y 3 millones, y el $37 \%$ de las almazaras cooperativas factura entre 300.000 y 1,2 millones. Además el 21,5\% de cooperativas oleícolas no factura más de 300.000 euros y en cambio un $13 \%$ de cooperativas de fruta dulce factura más de 12 millones de euros.

Cuadro 7. Facturación

\begin{tabular}{|l|l|l|l|l|}
\hline \multirow{2}{*}{ Euros } & \multicolumn{2}{|l|}{ Cooperativas fruta dulce } & \multicolumn{2}{l|}{ Cooperativas aceite oliva } \\
\cline { 2 - 5 } & $\mathbf{N}^{\mathbf{0}}$ cooperativas & $\%$ & $\mathbf{N}^{\mathbf{0}}$ cooperativas & $\%$ \\
\hline De 0 a 300.000 & 3 & 6,5 & 15 & 21,4 \\
De 300.000 a 1.2 millones & 12 & 26,1 & 26 & 37,1 \\
De 1.2 millones a 3 millones & 15 & 32,6 & 17 & 24,3 \\
De 3 a 6 millones & 7 & 15,2 & 3 & 4,3 \\
De 6 a 9 millones & - & - & 1 & 1,4 \\
De 9 a 12 millones & 6 & 13,0 & 3 & 4,3 \\
Más de 12 millones & 3 & 6,5 & 1 & 1,4 \\
NS/NC & - & - & 2 & 2,9 \\
\hline TOTAL & $\mathbf{4 6}$ & $\mathbf{1 0 0}$ & $\mathbf{7 0}$ & $\mathbf{1 0 0}$ \\
\hline \multicolumn{4}{|l|}{ Fuente: elaboración propia } \\
\hline
\end{tabular}

REVESCO N 108 - Segundo Cuatrimestre 2012 - ISSN: 1885-8031 - www.ucm.es/info/revesco 
Por tanto, podemos constatar que las cooperativas de fruta dulce generan una mayor facturación que las cooperativas oleícolas, puesto que el nivel de producción también es superior. Sin embargo a pesar de que las cooperativas frutícolas producen en mayor cantidad, este aspecto no se termina de trasladar a la facturación, lo que indica los enormes problemas de comercialización que tienen dichas entidades, sobretodo de trasladar el precio del agricultor al consumidor final, no pudiendo generar todo el valor añadido necesario.

A pesar de ello, estos resultados son similares a los obtenidos por las cooperativas agrarias catalanas en general. Según el Libro Blanco de la Economía Social en Cataluña, el perfil de cooperativa agraria que predomina, en términos de facturación, es la que mueve un volumen de negocio entre 300.000 y 2 millones de euros.

\subsection{Actividad Financiera}

En cuanto al nivel de formación del personal administrativo los resultados son similares en ambos tipos de entidades. En las cooperativas de fruta dulce, un 52,2\% tiene la formación profesional. Un 2,2\% no tiene formación, sin embargo tiene experiencia en el puesto que ocupa y un 32,6\% tiene formación a nivel universitario. Cabe destacar que en un $13 \%$ de los casos, la cooperativa no dispone de personal administrativo fijo y las tareas de administración y contabilidad son llevadas a cabo por un profesional independiente o una gestoría que realiza de forma periódica esta tarea. En las almazaras cooperativas, un 53\% tiene la formación profesional. Un 13\% no tiene formación, sin embargo tiene experiencia en el puesto que ocupa y un $21 \%$ tiene formación a nivel universitario. En un $11 \%$ de los casos, la almazara no dispone de personal administrativo fijo.

Respecto a la necesidad de financiación que pueda necesitar la cooperativa ${ }^{5}$, los resultados también son similares (figura 4). En ambos tipos de entidades, destaca el peso de la deuda frente a otros tipos de financiación propios, que pueden suponer para la empresa menos gastos financieros y por tanto mayor beneficio. Sin embargo, el tema financiero es un problema del que adolece la cooperativa en general, debido a la escasa capacidad que tienen estas entidades de generar ellas mismas autofinanciación. Así, la mayor parte de dichas

\footnotetext{
${ }^{5}$ En general, las fuentes de financiación de las cooperativas son: financiación vía socios, créditos de las Caja Rural, autofinanciación, sección de crédito, créditos oficiales y créditos bancarios.
} 
cooperativas se endeudan cuando necesitan recursos, y más de la mitad lo hacen a largo plazo (en un $51 \%$ en las almazaras cooperativas y en un 56,5\% en las cooperativas frutícolas).

Un $23,9 \%$ de las cooperativas de fruta dulce y un $21 \%$ de las almazaras cooperativas utiliza las reservas que genera para realizar inversiones. En general no suelen acudir al socio para pedir nuevas aportaciones, tan solo un $8,7 \%$ de las cooperativas de fruta y un $2 \%$ de las cooperativas de aceite de oliva lo hacen.

Figura 4. Formas de financiación por parte de las cooperativas

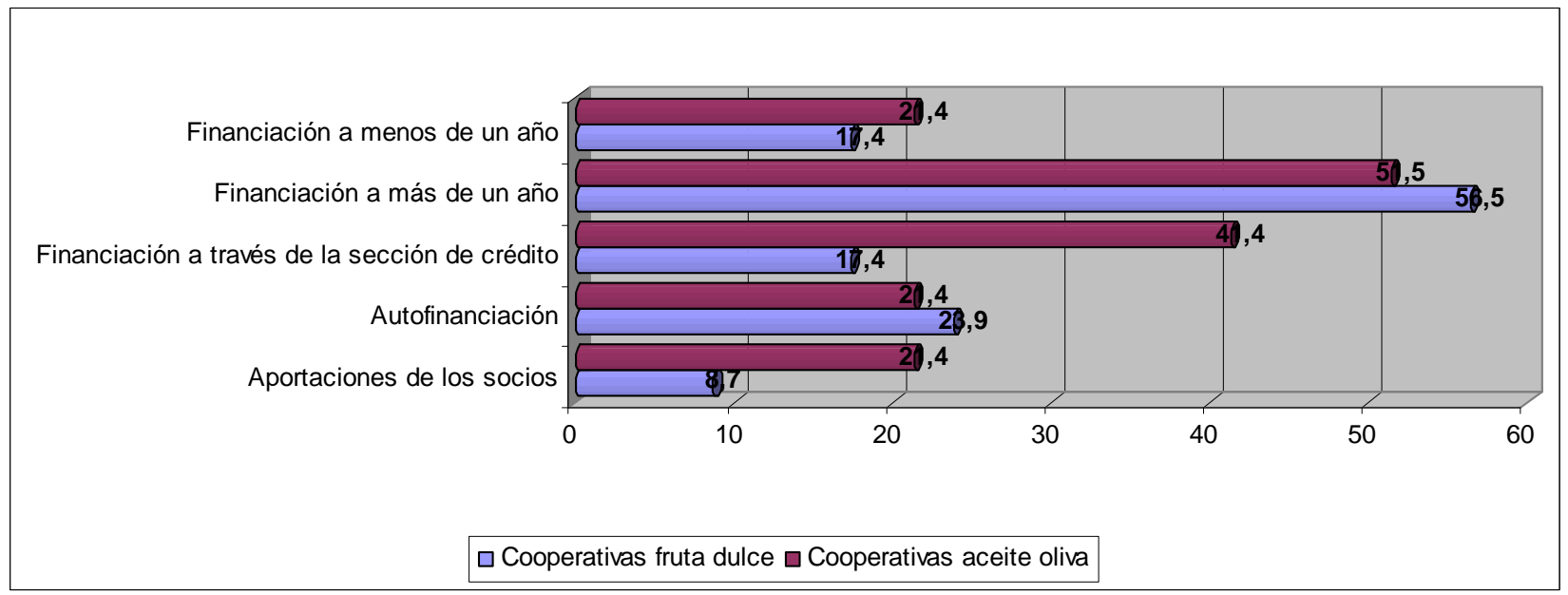

Fuente: elaboración propia

También hay que destacar que otra forma de financiarse la cooperativa, sin necesidad de acudir al exterior es a través de la propia sección de crédito de la entidad. Por tanto, aquellas cooperativas que disponen de sección de crédito, pueden utilizar esta vía para financiarse. En nuestro estudio, la utilizan el 17,4\% de las cooperativas de fruta dulce y el $41 \%$ de las almazaras cooperativas. Hay que tener en cuenta que no todas (como ya hemos comentado anteriormente) disponen de esta sección en la cooperativa, por lo que obligatoriamente deben acudir a otras fuentes.

Autores como Amat (1997) coinciden en que la sección de crédito es un elemento de máximo interés para las cooperativas agrarias. Los depósitos que los socios efectúan en la sección permiten una financiación más barata a la cooperativa y a los mismos socios, que a su vez, ven remunerados sus servicios mejor que en cualquier entidad financiera.

Como consecuencia de su actividad transformadora y comercializadora, las cooperativas generan unos ingresos con los que han de retribuir los factores productivos, el 
más importante de los cuales es, la producción aportada por el socio. La liquidación de la cosecha al socio se puede realizar por distintos procedimientos, sin embargo, los resultados de la encuesta nos confirman que el sistema que más utilizan las cooperativas frutícolas es el de precios de mercado $(56,5 \%)$. En la gran mayoría de los casos se discrimina por variedades $(87 \%)$ y se establecen penalizaciones por mala calidad $(91,3 \%)$. Por el contrario, el sistema que más utilizan las almazaras cooperativas es el de márgenes brutos (44\%). Dicho sistema consiste en restar de los ingresos los gastos de la campaña y dividir esta diferencia entre la cantidad de aceituna molturada. El valor resultante constituye el precio a pagar al socio, expresado en euros $/ \mathrm{kg}$.

\subsection{Actividad Comercial}

La preocupación de las cooperativas en general y las agrarias en particular, por la comercialización de los productos aportados por sus socios y su ubicación al inicio de la cadena agroalimentaria y, por tanto, alejadas de las señales que emite el consumidor final, propicia que las cooperativas adopten una orientación mucho más próxima a la producción que a la necesaria orientación al mercado (Schoreder et al. 1993; Arcas, 1999; Kyriakopoulos y Van Bekkum, 1999).

Analizando los resultados obtenidos en ambas investigaciones hemos podido comprobar como el ámbito de actuación de las cooperativas está muy diferenciado en función del tipo de producto que comercializa. En el caso de las cooperativas frutícolas se observa una significativa obertura a nuevos mercados en el extranjero. En el caso de la fruta un $45,7 \%$ de la producción se destina al mercado internacional. Aunque dicha cifra es importante, el tamaño de la empresa es determinante a la hora de analizar la presencia de la misma en el mercado exterior. En general, si bien hay entidades que participan en programas de exportación y llevan a cabo acciones puntuales en este sentido, se nota una importante carencia en muchas de estas entidades siendo necesario potenciar un aspecto tan crucial para las cooperativas productoras de fruta dulce que deseen crecer y expandirse.

Tal como se refleja en la figura 5, al mercado nacional se dirigen un 30,4\% de las cooperativas encuestadas. Dentro de España, gran parte de la producción se queda en Cataluña (69,6\%) seguido de la comunidad autónoma de Madrid (41,3\%). Un 37\% de la producción se destina al norte de España, un 30,4\% a la zona de Levante, un 28,3\% a 
Andalucía, un 19,6\% a Aragón, y únicamente un 15,2\% va dirigido a la zona de influencia de la cooperativa (o sea, un ámbito comarcal).

En cambio, y si nos centramos en las cooperativas oleicas, hemos podido comprobar como el ámbito de actuación de las almazaras cooperativas es eminentemente nacional, ya que tan solo un $13 \%$ se destina al mercado internacional. Dentro de España, gran parte de la producción se queda en Cataluña (64\%) y más concretamente en la propia comarca (50\%), por lo que podemos constatar que las ventas son mayoritariamente locales. En este sentido cabe tener en cuenta que los socios de la cooperativa, son a la vez proveedores y clientes, por lo que adquieren parte del aceite producido en la almazara. Por otro lado, la cada vez mayor presencia de agrotiendas en las propias cooperativas, origina que parte de las ventas se realicen en la propia almazara. Un 11\% de la producción se destina a Aragón, un $10 \%$ va al norte de España, aproximadamente un $8 \%$ de la producción se destina al Centro de España, Levante y Madrid y tan solo un 3\% va a Andalucía.

Figura 5. Destinos nacionales de la producción de las cooperativas catalanas de aceite y fruta

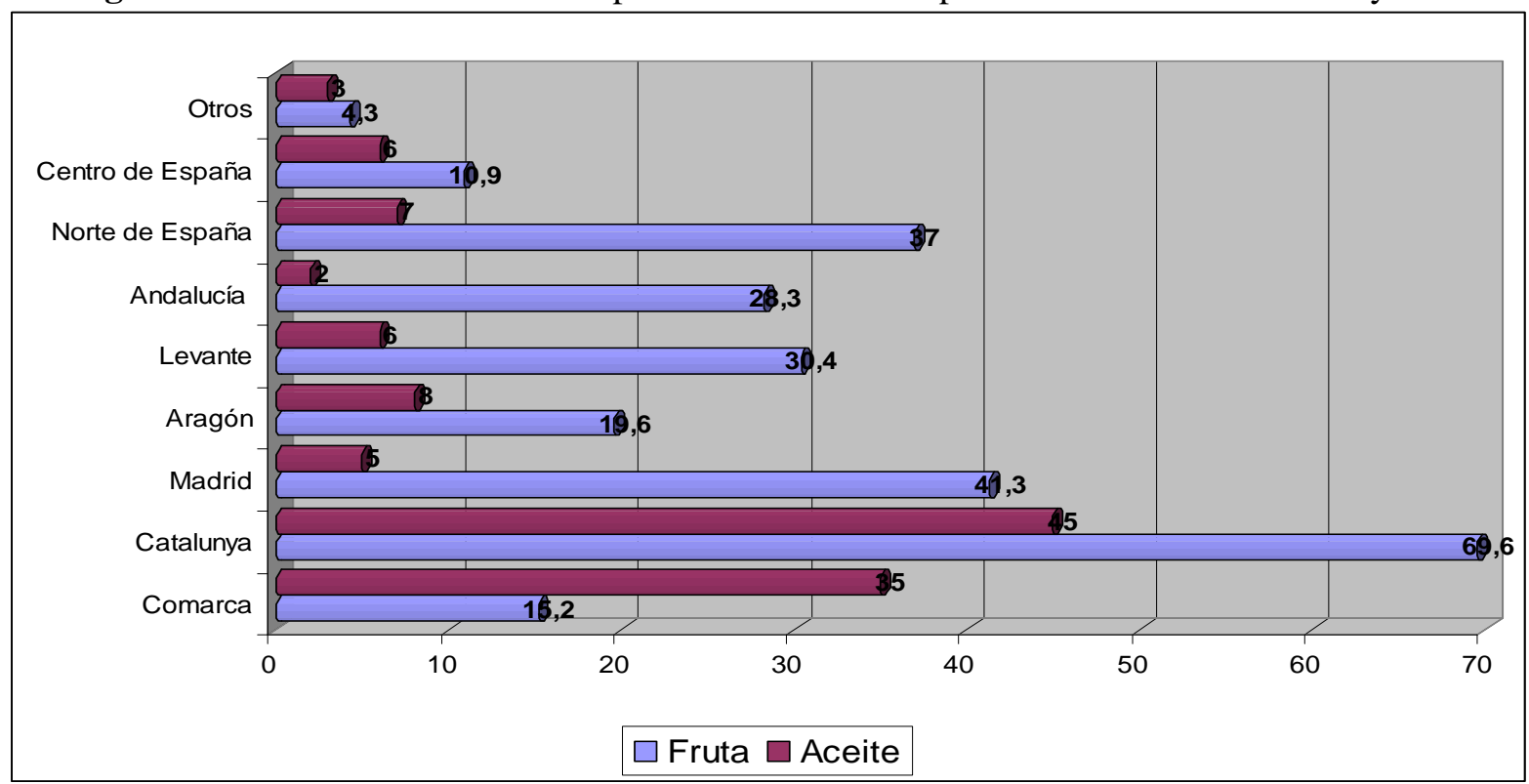

Fuente: elaboración propia

Si nos basamos en el mercado internacional, la mayor parte de la fruta se vende al mercado francés y alemán. Así un 34,8\% de las cooperativas exportan a Francia, un 30,4\% a Alemania, y un $21,7 \%$ a Inglaterra. En cambio, en el sector oleico, la mayor parte del aceite se vende al mercado italiano. Así un $13 \%$ de las cooperativas exportan a Italia, un $7 \%$ a Francia, otro $7 \%$ a Inglaterra, un $8 \%$ al mercado estadounidense, y de forma más marginal exportan a 
Australia, Países Nórdicos, Alemania y Holanda (figura 6). Fernández et al. (2008) destacan en su estudio sobre las cooperativas vitivinícolas, la importancia de la comercialización exterior y la diversificación de mercados entendida como la no concentración en un mercado sino en atacar muchos países.

Figura 6. Destinos internacionales de la producción de las cooperativas catalanas de aceite y fruta

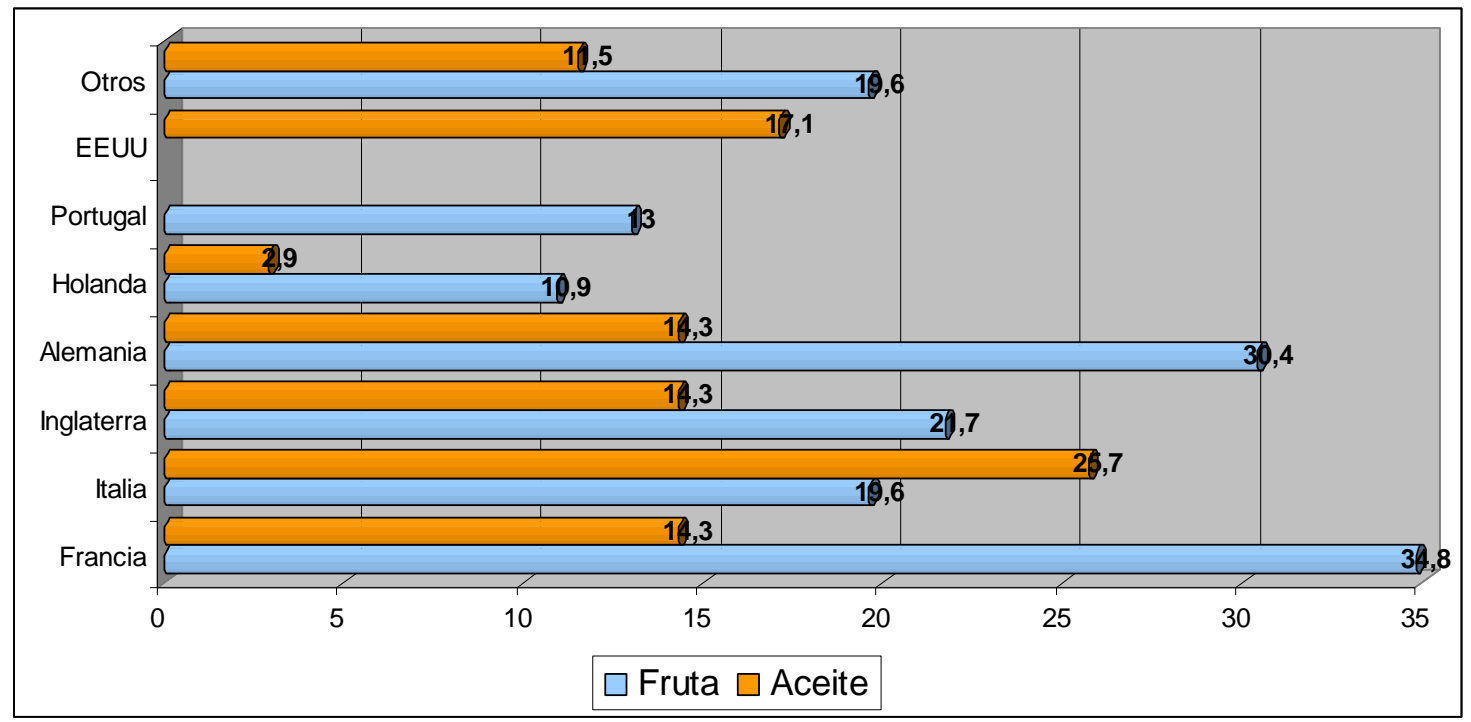

Fuente: elaboración propia

A nadie escapa la importancia de la comunicación publicitaria en la comercialización en general, y en la agrícola en particular. A este respecto, las cooperativas objeto de estudio no parecen haber captado la necesidad de esta herramienta esencial de marketing, puesto que pocas cooperativas realizan campañas de marketing. Tan solo un 10,9\% de las cooperativas de fruta la ha llevado a cabo en alguna ocasión y tan solo un $31 \%$ de las cooperativas de aceite. Las campañas son diseñadas principalmente por profesionales externos a la entidad en caso de las cooperativas de fruta y en cambio, en el caso de las almazaras, solo el $45 \%$ de los casos acuden a profesionales y en un 50\% las realizan internamente. Un dato interesante, es que un $4,5 \%$ de las mismas afirma tener departamento de marketing dentro de la cooperativa, y en este caso es dicho departamento el encargado de elaborar la campaña. Esta situación no se da en el sector oleico. En ambos sectores los objetivos de la campaña son básicamente dar a conocer el producto o la cooperativa e incrementar las ventas.

Si analizamos los instrumentos de marketing que las cooperativas consideran más importantes dentro de la gestión comercial, observamos una significativa coincidencia. En ambos sectores se destaca en primer lugar el producto, es decir, el diseño, la calidad, la marca, 
el envase, la etiqueta, el tamaño, etc. En segundo lugar el precio, en tercer lugar la distribución y finalmente la comunicación (publicidad, promociones, etc.).

A la hora de definir las características principales de su producto, las cooperativas analizadas coinciden en señalar la calidad del producto que ofrecen, como uno de los aspectos que consideran más importantes a tener en cuenta a la hora de vender el producto (ver cuadro 8). Tradicionalmente, la agricultura ha sido un sector de productos indiferenciados. Los esfuerzos para diferenciar el producto y obtener una ventaja competitiva por esa vía se han centrado esencialmente en la calidad. De hecho, y si nos centramos en el sector oleico, una de las características del producto aceite es su elevada calidad producida por la baja acidez del producto originada por los mecanismos de recolección de la aceituna y el proceso utilizado de molturación. Recordemos que las almazaras han realizado grandes esfuerzos para mejorar el sistema de producción del aceite incrementando la calidad del producto

Otro aspecto a valorar ha sido la variedad del producto. En el caso de las cooperativas de fruta un $15,2 \%$ valoran la variedad de la fruta. En un $10 \%$ de las cooperativa oleicolas, valoran el tipo de aceite como una característica clave en la comercialización.

Únicamente un 2,2\% de las cooperativas de fruta señalan la marca y un $7 \%$ de las de aceite indican la denominación de origen. En este sentido, se revela que las cooperativas no creen que un factor importante de venta del producto sea la marca o el hecho de pertenecer o no a una denominación de origen que es signo distintivo de marca y por tanto, en principio, debería mejorar la venta del producto.

Cuadro 8. Importancia en la venta por tipo de cooperativa

\begin{tabular}{|l|c|c|l|c|c|}
\hline \multicolumn{4}{|c|}{ Cooperativas aceite oliva } & \multicolumn{3}{c|}{ Cooperativas fruta dulce } \\
\hline Característica valorada & $\begin{array}{c}\text { Número de } \\
\text { cooperativas }\end{array}$ & $\%$ & Característica valorada & $\begin{array}{c}\text { Número de } \\
\text { cooperativas }\end{array}$ & $\%$ \\
\hline Tipo de aceite & 7 & 10 & La variedad de la fruta & 7 & 15,2 \\
Calidad del aceite & 54 & 77.1 & La calidad de la fruta & 34 & 73,9 \\
Envase & 2 & 2.9 & El aspecto de la fruta & 2 & 4,3 \\
Denominación de Origen & 5 & 7.1 & La marca & 1 & 2,2 \\
NS/NC & - & - & NS/NC & 2 & 4,3 \\
\hline TOTAL & $\mathbf{7 0}$ & $\mathbf{1 0 0}$ & TOTAL & $\mathbf{4 6}$ & $\mathbf{1 0 0}$ \\
\hline
\end{tabular}

El precio es una de las variables básicas dentro de las estrategias de marketing. El precio del producto depende del coste, de las técnicas de producción, del poder adquisitivo de los consumidores y de la política agrícola de la Unión Europea. A la hora de determinar el 
método de fijación de precios, observamos notables diferencias entre los diferentes sectores. Según los resultados de nuestros estudios, un 50\% de las almazaras cooperativas toma como referencia el precio que fijan otras cooperativas, un $20 \%$ lo calculan en función del margen que desean obtener sobre el coste del producto y un $16 \%$ establece que el precio ya viene predeterminado $^{6}$. En cambio en el sector frutícola, es de destacar que un $28,3 \%$ de las cooperativas afirman que fijan el precio de sus productos en función de lo que está dispuesto a pagar el consumidor, un $21,7 \%$ toma como referencia el precio que fijan otras cooperativas, un 19,6\% lo calculan en función del margen que desean obtener sobre el coste del producto, y finalmente un $13 \%$ establece que el precio ya viene predeterminado.

En base a los resultados podemos considerar las cooperativas de fruta tienen un margen más amplio a la hora de fijar su política de precios, que las cooperativas de aceite. Las primeras tienen en cuenta aspectos como la demanda y la competencia, y las segundas, se fijan en la competencia, pero sin olvidar los costes y el precio prefijado.

Los canales de distribución que utilizan las cooperativas estudiadas son variados y diversos en función del tipo de cooperativa (ver figura 7). En el caso del sector del aceite de oliva, el 55\% de las cooperativas distribuyen el producto a través del propio establecimiento. En cambio en el sector frutícola, la mayoría de las cooperativas $(56,5 \%)$ distribuyen el producto a través de distribuidores o representantes. Esta diferencia viene explicada porque gran parte de las cooperativas disponen de agro tienda lo que les permite la venta directa de los productos que elaboran, a los propios productores o a personas que tienen tradición de ir a buscar el aceite al molino. Además, como ya hemos indicado, no se trata, en general, de empresas de gran dimensión, siendo el nivel de producción reducido.

Si seguimos con las cooperativas de aceite, el 24\% utiliza distribuidores, un $4 \%$ dispone de red propia de ventas (que cabe pensar que son aquellas cooperativas de mayor dimensión que generan grandes volúmenes de producción), un 9\% utiliza Internet para realizar ventas y un $17 \%$ vende a través de entidades de segundo grado (almazaras cooperativas de primer grado que se encuentran asociadas a la sección de aceite de una almazara cooperativa de segundo grado, a la que venden el exceso de producción).

\footnotetext{
${ }^{6}$ Las cooperativas que suelen partir de un precio prefijado normalmente son aquellas que están asociadas a una Denominación de Origen. En este caso, es la propia denominación la que fija un precio mínimo que deben respetar todas las cooperativas que forman parte de ella, entre otras condiciones.
} 
En cuanto a las cooperativas de fruta, el 28,3\% comercializa su producción a través de cooperativas de segundo grado y el $21,3 \%$ lo hacen en el propio establecimiento. Estos resultados indican, tal como dice Cook (1997), que la mayor parte del comercio de producto fresco es manejado a través de intermediarios.

En este sentido cabe destacar que dichas entidades no utilizan de forma generalizada la cooperativa de segundo grado para realizar sus ventas, cuando en realidad, dicha figura tiene como finalidad la comercialización conjunta del producto que generan las cooperativas de primer grado, para poder negociar en mejores condiciones los precios, así como disponer de mejores canales de comercialización. Además este comportamiento comercial pasivo, alejado de lo que es la orientación al mercado, se traduce en un distanciamiento por parte de la cooperativa de los mercados finales y por tanto de los clientes.

Por otro lado, y para resaltar las diferentes vías de comercialización, destacar que un 19,6\% de las cooperativas frutícolas comercializan sus productos directamente a los supermercados o a los pequeños comercios, mientras que tan solo un $2 \%$ de la producción de aceite se destina a este tipo de establecimientos. Esto significa que las almazaras cooperativas tienen poca presencia en los lineales de los establecimientos minoristas, siendo las grandes empresas de distribución del sector agroalimentario, las encargadas de colocar el aceite en este nicho de mercado. La escasa dimensión del sector y la gran atomización del mismo, las colocan en escasa desventaja para negociar el producto y competir con las grandes firmas. 
Figura 7. Canales de venta utilizadas por las cooperativas

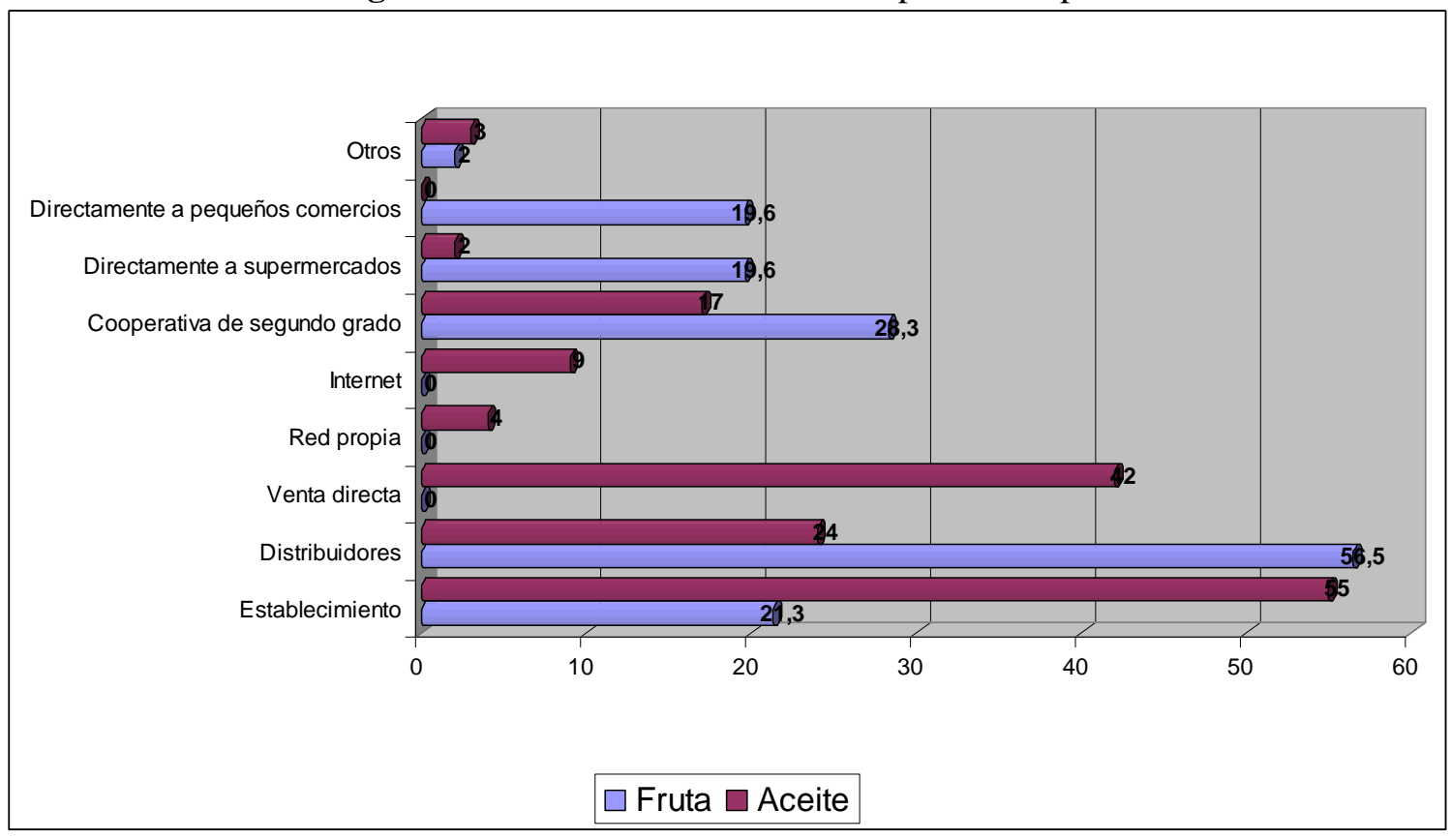

Fuente: elaboración propia

Finalmente, señalar que un canal de venta con un gran potencial como es Internet prácticamente no se cita en el caso de la fruta, aunque en el sector aceite, lo señalan un discreto 9\%. Estos datos indican la escasa innovación tecnológica de las cooperativas en este campo.

En cuanto a las estrategias de promoción, la demanda de un producto agrario de alimentación como puede ser el aceite o la fruta, depende del precio pero también de la publicidad y de otros esfuerzos de promoción, sobretodo si tenemos en cuenta la gran presencia de productos sustitutivos en el mercado. Pero a la hora de poner en práctica estas estrategias observamos significativas diferencias entre las cooperativas de los dos sectores. En el caso del sector del aceite de oliva es muy marquista, situación que no se da en el ámbito frutícola. El público se inclina por marcas bien conocidas de aceite de oliva como garantía del producto. Por este motivo la promoción no solo debe introducir al público en el aceite de oliva virgen sino que se le debe ofrecer una marca fácil de recordar (Fortuny, 2002). En este sentido, cabe tener en cuenta que prácticamente todas las almazaras cooperativas catalanas ofrecen su aceite con marca propia. Pero este exceso de marcas desorienta al consumidor, por lo que dichas entidades deben realizar grandes esfuerzos para promocionar el producto. 
En cuanto al sector frutícola, los datos de Panel de Consumo Alimentario del Ministerio de Agricultura, Pesca y Alimentación, revelan importantes descensos en el consumo de fruta, aunque parece haberse detenido esta tendencia en los últimos años. Y es que existe toda una gama de productos entre los que se encuentran los lácteos, los dulces y postres preparados o los snacks que tienen una intensa acción de marketing. Dichos cambios en el consumo de frutas y sus sustitutivos se justifican por los cambios en el comportamiento general de los consumidores, la estructura de la población, composición de los hogares, las modas y los hábitos de consumo, los estilos de vida o la importancia de los productos ecológicos, entre otros (Planells y Mir, 2002).

También se detectan importantes diferencias en el uso de los canales de comunicación y promoción que utilizan las cooperativas agrícolas para dar a conocer el producto (ver figura 8). En el caso de las almazaras se incide en los diarios y revistas (46\%), catálogos (25\%), radio $(38 \%)$, carteles informativos $(22 \%)$ y la presencia en ferias nacionales (36\%). Muy pocas cooperativas oleicolas acuden a ferias internacionales para promocionar sus productos (10\%) y tampoco suelen utilizar la televisión como medio de comunicación (4\%).

En cambio, en las cooperativas de fruta también se utilizan los diarios y revistas $(21,7 \%)$ como la principal vía de difusión pero tienen una presencia significativa, las ferias internacionales $(15,2 \%)$, Internet $(13 \%)$, catálogos $(10,9 \%)$ y carteles informativos $(10,9 \%)$. Un hecho a destacar es que $34,8 \%$ de las cooperativas de fruta afirman no utilizar ningún medio de comunicación. En el sector del aceite este dato es menor (9\%). Los mercados de productos frescos todavía están orientados hacia el producto, con bajos niveles de publicidad para los consumidores y con la mayoría de las empresas que actúan como precio-aceptantes ${ }^{7}$.

\footnotetext{
${ }^{7}$ Estos resultados son similares a los obtenidos por la Confederación de Cooperativas Agrarias de Cataluña en el Observatorio del Cooperativismo (2004) donde el 65\% de las cooperativas agrarias utilizan la publicidad en revistas y catálogos para difundir su actividad, el $57 \%$ utiliza la asistencia a ferias y muestras, el $57 \%$ la página web, el $54 \%$ folletos, el $42 \%$ la tarjeta y el $11 \%$ otros instrumentos.
} 
Figura 8. Canales de promoción utilizados por las cooperativas

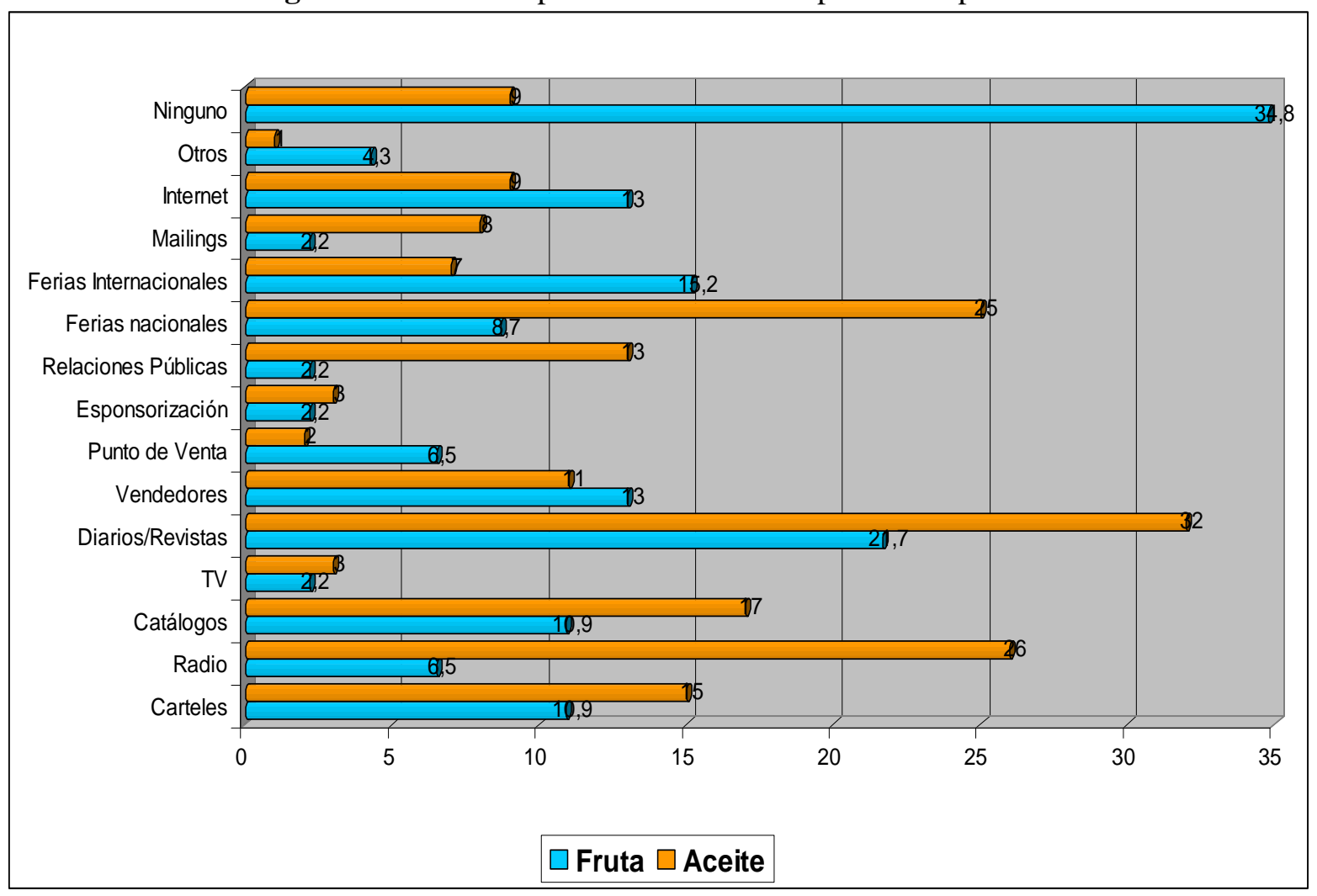

Fuente: elaboración propia

Existe una apreciación general en el sentido de que la publicidad basada en acciones puntuales es poco útil y en el caso de hacerse de manera general, ésta debería ser muy intensa, lo cual supone unos costes a los que no pueden hacer frente las cooperativas de forma individual. Si bien se ven con buenos ojos las acciones institucionales llevadas a cabo, las consideran insuficientes siendo necesario potenciarlas, sobretodo debido a la fuerte publicidad que realizan las grandes empresas de distribución y de productos sustitutivos.

La percepción sobre la efectividad que tienen los diferentes canales de comunicación sobre el consumidor, también difiere en función del tipo de producto. Así que en el caso del aceite de oliva, podemos observar como un $56 \%$ afirma que dichas actuaciones son efectivas y tienen éxito. En el caso de la fruta, únicamente representa un 37\%. En cambio un 41,3\% de las cooperativas de fruta considera que realmente no repercuten en un incremento de las ventas y un 21,7\% no sabe cual es el impacto que los canales de promoción y publicidad que utilizan tienen sobre el consumidor y por tanto como afectan a las ventas del producto que ofrecen. Estas cifras son un $25 \%$ y un $19 \%$ respectivamente al tratarse del sector del aceite de oliva. 
En ambos sectores, las cooperativas que consideran que las campañas de marketing no tienen éxito, en ningún caso creen que el motivo de fracaso de las campañas publicitarias sea debido a un mal diseño de la campaña, sino a la falta de presupuesto por parte de dichas entidades. También es significativo que un número importante de cooperativas, tanto de fruta como de aceite afirman desconocer el motivo de porque la campaña no ha alcanzado los objetivos señalados

Con la llegada de las nuevas tecnologías de la información y la comunicación, Internet se está convirtiendo en un nuevo mecanismo que utilizan las empresas para dar a conocer e informar sobre los distintos productos que ofrecer. Actualmente, muchas son las firmas que utilizan Internet como anuncio publicitario y como mecanismo para formular pedidos.

Si nos centramos en los resultados del estudio (ver figura 9), podemos corroborar como la gran mayoría de las cooperativas disponen de conexión a la Red (un 93,5\% de las cooperativas de fruta y un $87 \%$ de las cooperativas de aceite de oliva). Los principales usos que estas cooperativas conectadas a la Red hacen de Internet son el uso del correo electrónico, búsqueda información, enviar o recibir datos, realizar transacciones financieras, y llevar a cabo trámites con la administración.

Destacar que solo una reducida parte de estas cooperativas lo utiliza para realizar ventas (un 11,6\% en el caso de la fruta y un $10 \%$ en el caso del aceite). Otro uso importante es la promoción de la empresa (representa el 27,9\% y el 26\% respectivamente).

Por tanto, a pesar de que un gran número de cooperativas disponen de Internet en el centro, no acaban de aprovechar las enormes ventajas que ofrece este sistema, y lo utilizan básicamente para tareas administrativas y de control, dejando al margen otras funciones relacionadas con la comercialización como podría ser crear una gran página Web para promocionar el producto (solo un 32,6\% de las cooperativas de fruta y un $34 \%$ de almazaras tienen Web propia), realizar ventas a escala más amplia, analizar el mercado, etc. Pensamos que por un lado la falta de presupuesto (como ya hemos indicado) de dichas entidades les supone un freno para realizar actividades de este tipo, y por otro, la falta de mentalidad comercial que no caracteriza precisamente a este tipo de empresas, que hacen prevalecer las funciones de producción sobre las de comercialización. 
Según Boccherini (2010) el sector agroalimentario se enfrenta a un entorno competitivo complejo y difícil, en el que el bajo crecimiento del consumo y la abundancia de oferta presionan los precios a la baja, y aunque las empresas españolas presentan un buen nivel de calidad, seguridad alimentaria y competitividad también acusan importantes debilidades por su reducido tamaño y deficiente orientación al mercado.

Además podemos destacar que las cooperativas que disponen de Web propia, tampoco la actualizan periódicamente, sino que lo hacen con poca frecuencia (62\% de las cooperativas de aceite y $57,1 \%$ de las de fruta), por lo que tampoco destinan el tiempo necesario para mejorar dicha página, así como la información que puedan ofrecer. Su finalidad está en asegurar la presencia, de modo testimonial, de la empresa en Internet, aunque de un modo poco elaborado puesto que no constituye ninguna herramienta estratégica para la firma.

Figura 9. Usos de Internet

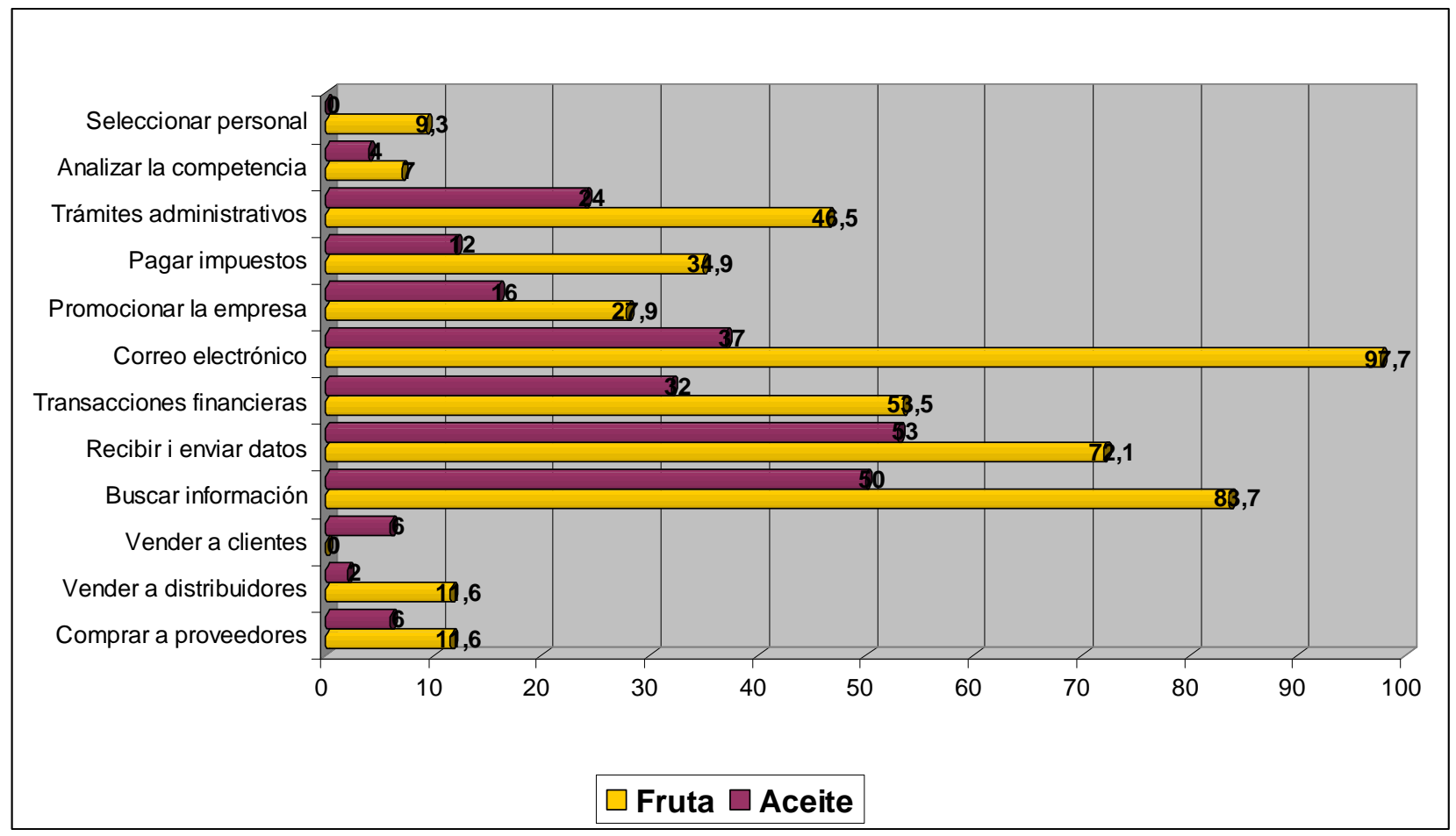

Fuente: elaboración propia

Estos resultados son similares a los obtenidos en otros estudios. Meroño y Arcas (2006) establecen que la mayor parte de las cooperativas agroalimentarias disponen de Internet, y un $40 \%$ declaran contar con sitio web. Sin embargo tan solo un 5\% declaran disponer de alguna utilidad de comercio electrónico, porcentaje que se eleva hasta el $12 \%$ de las que disponen sitio web. Mozas y Bernal (2001) indican que el 95\% de las cooperativas de segundo grado españolas tienen acceso a Internet (el 44\% tienen su propia página web), pero 
solamente el $7 \%$ realiza ventas online, el $9 \%$ compra a proveedores y el $75 \%$ intercambia información con clientes y proveedores a través del correo electrónico.

En resumen, la comparación del uso de tecnologías de la información revela un uso similar de las empresas agrarias en las aplicaciones de gestión y un uso algo inferior de Internet. Así quizá se debería actualizar la imagen de un mayor retraso tecnológico de las empresas agrarias basada en la existencia de unos factores inhibidores como el carácter tradicional, la influencia de la localización rural, la escasa formación del empresario, la pequeña dimensión de las explotaciones agrarias y su elevada dispersión, etc. (Mozas y Bernal, 2001; Briz y Laso, 2001). Posiblemente la perspectiva más apropiada para enfocar el análisis del empleo de las tecnologías de la información en las empresas agrarias sea el del tamaño, aunque también deban ser considerados ciertos rasgos sectoriales.

\section{CONCLUSIONES}

Las cooperativas productoras de aceite de oliva y fruta dulce, han sido y continúan siendo una pieza fundamental para el desarrollo del sector agrario en muchas zonas de Cataluña, constituyendo uno de los principales agentes dinamizadores en zonas rurales en términos de actividad económica y servicios.

Si realizamos una comparación entre ambos sectores podemos establecer que si bien existen similitudes y divergencias entre ambos sectores, debido sobretodo al tipo de producto que ofrecen, tanto las cooperativas de aceite de oliva como de fruta dulce adolecen de problemas similares. La reducida dimensión de dichas entidades, las dificultades financieras de las mismas, las carencias formativas en sus cuadros directivos y el escaso interés por la inbternacionalización, son factores que dificultan el crecimiento y expansión de dichas sociedades.

Cabe tener presente que el mercado de productos agrarios ha experimentado enormes cambios en los últimos años. Por ello, las cooperativas agrarias objeto de estudio también han realizado enormes esfuerzos para adaptarse a las nuevas exigencias, sobretodo en innovación y calidad. Han ido introduciendo paulatinamente formas de colaboración entre ellas, la figura del gerente va cobrando cada vez más importancia y van introduciendo en la medida de sus posibilidades medidas que mejoren la comercialización. 
Sin embargo, con los problemas actuales que presentan actualmente los mercados (saturación de la oferta, fuerte competencia, bajos precios, etc.) deben realizar enormes esfuerzos para incrementar su dimensión bien a través de acuerdos de cooperación o integración en entidades de segundo grado, generar un mayor valor añadido y mejorar la comercialización con el fin de llegar más directamente al consumidor final. De este modo la apertura a mercados exteriores resultará de gran importancia para dichas cooperativas agrarias que comercializan productos de gran calidad.

\section{BIBLIOGRAFÍA}

ALVAREZ, J.; CAMACHO, F.: Innovaciones en el sector hortofrutícola español. Editado por Ministerio de Agricultura, Pesca y Alimentación, 2003, Madrid, pp. 222.

AMAT, O.: Estudi socioeconòmic de les cooperatives a Catalunya. Generalitat de Catalunya. Departament de Treball. 1997, pp. 630

ARCAS, N.: El marketing de las cooperativas agrarias. Claves para el desarrollo de las empresas agrarias. Ciriec-España, Revista de Economía Pública, Social y Cooperativa, 1999.

AULAKH, P.S.; KOTABE, M.; YTEEGEN, H.: Exports strategies and performance of firms from emerging economies: evidence from Brazil, Chile and Mexico. Academy of Management Journal, 43(3), 2000, pp. 342-361.

BAREA, J.; MONZÓN, J.L.: Libro blanco de la economía social en España. Centro de Publicaciones del Ministerio de Trabajo y Asuntos Sociales, 1992, Madrid.

BARRIACH, J.: Cooperativisme agrari a les comarques meridionals. Jornades agràries de les comarques meridionals. Réus 1980. Obra Social de la Caixa de Pensions. 1981, Barcelona. Pp. 127-131.

BOCCHERINI, J.A.: Nuevos retos competitivos para la cadena agroalimentaria española, pp. 17-27 en MERCASA. Ed. Ministerio de Médio Ambiente, Rural y Marino, 2010, Madrid.

BRIZ, J.; LASO, I.: Internet y comercio electrónico. Mundi Prensa y ESIC, 2001, Madrid.

CONFEDERACIÓ DE COOPERATIVES AGRARIES DE CATALUNYA: Observatori del cooperativisme. Estudi dels perfils de les cooperatives catalanes, 2004, Barcelona. Documento disponible en http://laconfederacio.cooperativescatalunya.coop/

CABALLER, V.; JULIÀ, J.F.; SEGURA, B.: Economía de la cooperativa hortofrutícola. M.A.P.A. Dirección General de la Producción Agraria. 1985, Madrid. Pp. 204. 
COOK, L.: Tendencias internaciones en el sector de frutas y hortalizas frescas. Economía Agraria, no 181, 1997, pp. 183-208.

CRISTÓBAL, E.; MONTEGUT, Y.; MARIMON, F.: La gestión de las cooperativas agrarias: tipificación de las cooperativas del sector oleícola de Cataluña. Ciriec-España, Revista de Economía Pública, Social y Cooperativa, nº 59, 2007, pp. 203-236.

DEL PINO, A.: Tendencias tecnológicas en el sector agroalimentario. Economía Industrial, $\mathrm{n}^{\circ}$ 342, 2001, pp. 39-46.

FEDERACIÓ DE COOPERATIVES AGRARIES DE CATALUNYA (FCAC): Anuari Socioeconòmic de les Cooperatives Agraries de Catalunya, 2009. 2010, Barcelona. Documento disponible en http://www.fcac.coop/

FERNANDEZ M.V.; PEÑA, I., HERNÁNDEZ F.: Factores determinantes del éxito exportado. El papel de la estrategia exportadora en las cooperativas agrarias. CiriecEspaña, Revista de Economía Pública, Social y Cooperativa, nº 63, 2008, pp. 39-64.

FORTUNY SANTOS, J.: Metodología del análisis sectorial en el sistema agroalimentario, aplicada al subsector oleícola catalán. Evaluación de la competitividad, el progreso tecnológico y la eficiencia económica empresarial. Tesis Doctoral. Universidad Politécnica de Cataluña. 2002, Barcelona. pp. 951.

GALDEANO, E.: Estudio de competitividad de las entidades asociativas andaluzas de comercialización hortofrutícola. Universidad de Almería y Consejería de Empleo y Desarrollo Tecnológico, 2000.

GALDEANO, E.: Tendencias y estrategias competitivas de las entidades asociativas de comercialización agroalimentaria. Revista Europea de Dirección y Economía de la Empresa, 10 (1), 2001, pp. 141-161.

GALDEANO, E.: Competitividad de las cooperativas hortofrutícolas: análisis del impacto económico de las acciones de calidad y medioambientales en las OPFH andaluzas. CiriecEspaña, Revista de Economía Pública, Social y Cooperativa, no 41, 2002, pp. 53-83.

GENERALITAT DE CATALUNYA: Llibre blanc de l'economia social a Catalunya. Departament de Treball de la Generalitat de Catalunya. 2001, Barcelona.

GÓMEZ ESPÍN, J. Mª .: Estrategias de innovación en el sector hortofrutícola español y en las empresas encargadas de la logística y transporte de estos productos perecederos. Papeles de Geografía, nº 39, 2004, pp. 81-117.

HEIJBROEK, A.M.A.; VAN DIJK, J.B.; VAN PELT, A.J.; BOOT, E.C.A.H.: El mundo del comercio mundial de frutas frescas. Investigación sobre alimentación y agribusiness, Rabobank Internacional, Investigación sobre alimentación y agribusiness, 1997. 
KYRIAKOPOULOS, K.; VAN BEKKUM, O.F.: Market orientation of European Agricultural Cooperatives: strategic and structural issues. IX European Congress of Agricultural Economists, Warsaw, Poland, 1999, pp. 148-164.

LOPEZ, M.; LOPEZ, F.: Los métodos de liquidación en las cooperativas hortofrutícolas.

Ciriec- España, Revista de Economía Pública, Social y Cooperativa, no 58, 2007, pp. 131159.

LUCIER, G.; POLLACK, S.; PÉREZ, A.: Penetración de las importaciones en la industria de frutas y hortalizas de los Estados Unidos. Servicio de Investigación Económica, Ministerio de Agricultura de los Estados Unidos. Informe sobre la situación y perspectivas de las hortalizas. Noviembre 1997.

MAPYA: Libro Blanco de la Agricultura y el Desarrollo Rural. Ministerio de Agricultura, Pesca y Alimentación, 2002, Madrid. Documento disponible en http://www.libroblancoagricultura.com/

MEROÑO, A.; ARCAS, N.: Equipamiento y gestión de las tecnologías de la información en las cooperativas agroalimentarias. Ciriec-España, Revista de Economía Pública, Social y Cooperativa, $\mathrm{n}^{\circ}$ 54, 2006, pp. 5-31.

MINISTERIO DE MEDIO AMBIENTE Y MEDIO RURAL MARINO: Observatorio del Consumo y de la Distribución Alimentaria, 2008, Madrid. Documento disponible en http://www.marm.es/

MONTEGUT Y.; CRISTÓBAL E.; MARIMON F.: The singularity of agrarian cooperatives management: cooperatives' typologies in the olive oil sector in Spain. International Journal of Business and Management. Vol. 6, No 6, June 2011._ISSN: 1833-385

MONTEGUT, Y.; CRISTÓBAL, E.: Análisis empresarial de las cooperativas del sector de la fruta dulce de Cataluña. REVESCO: Revista de Estudios Cooperativos. $\mathrm{n}^{\circ}$ 101, Primer Cuatrimestre 2010, p. 28-57

MONTEGUT, Y.; CRISTÓBAL, E.: Ús d'internet en les cooperatives de fruita dolça catalanes. Fòrum Empresa, 2009, pp. 20-22.

MOYANO, J.; HIDALGO, F.A.: El impacto de la dimensión en la sociedad cooperativa agraria. Una aplicación al cooperativismo oleícola. Revista de estudios cooperativos, 73, 2001, pp. 95-121.

MOZAS, A.: Las cooperativas agrarias y su entorno competitivo: una aproximación empírica". Revista de estudios cooperativos, 72, 2000, pp. 215-233. 
MOZAS, A.; BERNAL, E.: El impacto de las nuevas tecnologías en el cooperativismo agrario-alimentario: perspectivas de futuro. Revesco, Revista de Estudios Cooperativos, $\mathrm{n}^{\circ}$ 73, 2001, pp. 123-147.

NIETO, M.: Bases para el estudio del proceso de innovación tecnológica en la empresa. Ediciones de la Universidad de León, 2001, León. Pp. 265.

PLANELLS, J. M.; MIR, J.: La agroexportación ante la nueva distribución alimentaria. La agricultura mediterránea del siglo XXI. Colección Mediterráneo Económico, $\mathrm{n}^{\circ} 2$. Edita Cajamar. 2002, Almería.

RUBEN, R.: Vertical markets and co-operative Hierarchies: the role of co-operatives in the agri-food industry markets. European Review of Agricultural Economics, vol 34, issue 4, 2007, pp. 541-544.

RUIZ JIMENEZ, C.; HERNÁNDEZ M. J.; GARCÍA, E.: Estado actual de la investigación sobre sociedades cooperativas agrarias en España, Ciriec-España, Revista de Economía Pública, Social y Cooperativa, $\mathrm{n}^{\circ}$ 56, 2006, pp. 65-86.

SCHOREDR, B.; WALLACE, T.; NAVONDO, F.: Cooperatives, Statutory: marketing organisations and global business strategy". Agribusiness, vol 9, n 2, 1993, pp. 175-187.

SEGURA, B.; SERVER, R.: Situación económica y financiera de las Organizaciones de productores de frutas y hortalizas (OPFH) en la Comunidad Valenciana. Investigación Agraria, vol 5 (1), 1990, pp. 19-37.

SERRAT I OLIVERAS, A.: Implantación, estructura y problemas del cooperativismo agrario en Catalunya. Problemas de actuación. Conferencia pronunciada en la Universidad de Verano Menéndez Pelayo en Sitges, 1986.

SHOHAM, A.: Bounded rationality, planning, standardization of international strategy and export performance: a structural model examination. Journal of International Marketing, 7, 1999, pp. 24-50.

TOUS, J.: El olivo. Situación y perspectivas en Tarragona. Ed. Diputación de Tarragona. 1990, Tarragona. Pp. 376.

TOUS, J.; ROMERO, A.: Variedades del olivo. Ed. Fundación "La Caixa”. AEDOS. 1993, Barcelona, $172 \mathrm{p}$.

TOUS, J.; ROMERO, A.: La nova olivicultura de Catalunya". Butlletí informatiu. Institut de Recerca i Tecnologia Agroalimentàries, n 43, Julio 1994.

TOUS, J.; ROMERO, A.: Aceites catalanes. Denominaciones de Origen. Olivicultura Jornadas Técnicas. Fundació La Caixa y Agrolatino. 1994, Barcelona. 
VIDAL, F.: Eficiencia económica de las cooperativas de comercialización hortofrutícola de la Comunidad Valenciana. Tesis doctoral. Universidad Politécnica de Valencia. 1999, Valencia.

VIDAL, F.; DEL CAMPO, F.; SEGURA, B.: Caracterización empresarial del cooperativismo de comercialización hortofrutícola de la Comunidad Valenciana: un análisis provincial. Ciriec-España, Revista de Economía Pública, Social y Cooperativa, n 34, 2000, pp. 7194.

VILÀ, J.; FARRÁN, J.: El aceite de oliva: la provincia de Lleida. Nota técnica de la División de Investigación del IESE. Universidad de Navarra. 1991, Barcelona. 